Portland State University

PDXScholar

7-12-1988

\title{
Eating Disorders: The Correlation of Family Relationships with an Eating Disorder Continuum
}

Jana Schweitzer

Portland State University

Follow this and additional works at: https://pdxscholar.library.pdx.edu/open_access_etds

Part of the Dietetics and Clinical Nutrition Commons, Family, Life Course, and Society Commons, and the Psychology Commons

Let us know how access to this document benefits you.

\section{Recommended Citation}

Schweitzer, Jana, "Eating Disorders: The Correlation of Family Relationships with an Eating Disorder Continuum" (1988). Dissertations and Theses. Paper 3844.

https://doi.org/10.15760/etd. 5716

This Thesis is brought to you for free and open access. It has been accepted for inclusion in Dissertations and Theses by an authorized administrator of PDXScholar. Please contact us if we can make this document more accessible: pdxscholar@pdx.edu. 
AN ABSTRACT OF THE THESIS OF Jana Schweitzer for the Master of Science in Psychology presented July 12, 1988.

Title: Eating Disorders: The Correlation of Family Relationships with An Eating Disorder Continuum. APPROVED BY MEMBERS OF THE THESIS CǾMMITTEE:

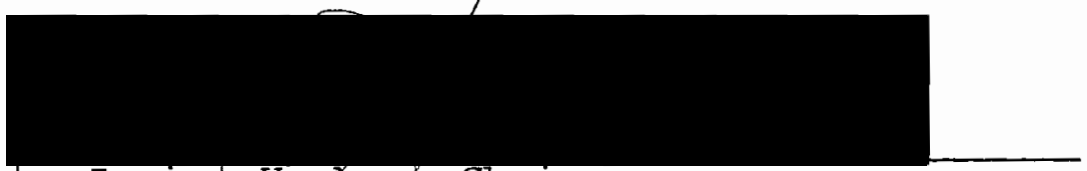
Janice Haaken, Chairperson

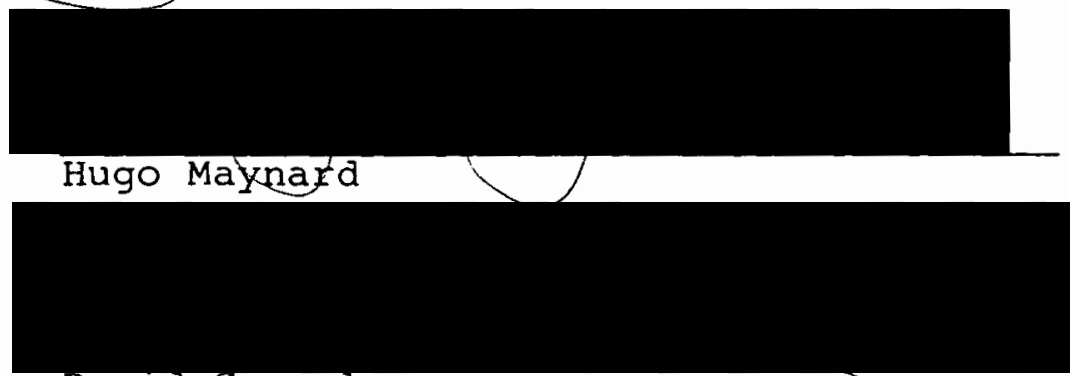

David cressier

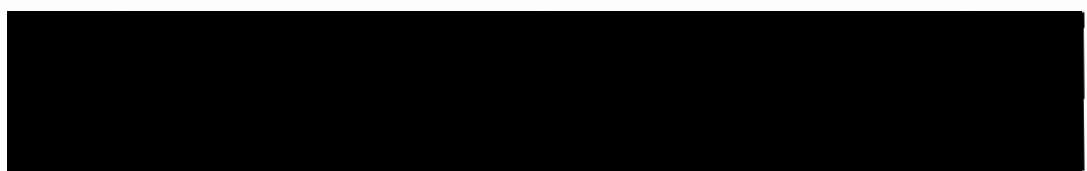

Leslie McBride

For the purposes of this study, eating disturbances were placed on a continuum ranging from disordered to normal, and family factors were examined via this framework. Research on anorectics and bulimics indicates that a variety of family variables contribute to the etiology of eating disorders. Research suggests the presence of a subgroup of persons who experience some 
disturbance in their relationships with food but not to the severity observed among eating disordered individuals. This study examined the relationship between family factors and eating disturbances.

A sample of male and female college students (overall $n=168$, male sample $n=78$, female sample $n=90$ ) was drawn from four undergraduate psychology courses at a large urban university. Subjects completed a questionnaire comprised of demographic questions, two eating disorder sections, and three family relationship sections, all derived from preexisting questionnaires with established reliability and validity indices. Scores on the eating disorder portion determined placement along the continuum.

In addition to normal and disordered groups, a large subgroup demonstrating what might be classified as an intermediate disturbance was formed from scores of both female and male subjects. The disparate sizes of the three criterion groups prevented direct comparisons, so they were examined on a continuum basis.

Multiple regression analyses on the relationship between various family and eating disorder variables were computed. Family conflict was found to be strongly associated with the presence of an increased eating disturbance for both the male and female samples. Overall 
family cohesion was a less strong factor than family conflict. Females were more sensitive to a noncohesive family environment, whereas men were more sensitive to an overly-cohesive family. Increased severity of eating disturbances was correlated with a chaotic family for females. It was not possible to determine whether the eating disturbance was antecedent or consequent to the family chaos. Females demonstrated an increased eating disturbance in association with their mother's

out-of-the-home employment; however, this was a relatively insignificant contributing factor when combined with other family factors. A greater eating disturbance in males was associated with a higher degree of involvement by their fathers; father's involvement was nonsignificant for women. Attitude towards mother was found to be nonsignificant in relationship to an increased eating disturbance for both the females and males. The attitude towards the father was more significant in association with the presence of an eating disorder for both samples, but the family variables of conflict and cohesion held even more weight. Analysis of the subdimensions of the eating disorder experience indicated that females attempted to manage personal needs and empower themselves through their manipulations with food while males showed bulimic 
tendencies in association with ambivalent feelings about their families. Males also showed a stronger correlation between feelings about a small change in weight and degree of eating disorder than the females. Males are therefore seen to be more preoccupied with food and body image than has been reported in the literature.

As many of the above findings, although significant, accounted for only a small percentage of sample variance among eating disordered scores, suggestions for subsequent research are offered. Limitations of the questionnaire are examined. The need for new research tools is discussed as is the need to utilize research tools in a variety of combinations to explore in greater detail the significance attributed to the findings. The high incidence of intermediate eating disturbances identified in this study indicates that this area warrants further study. The higher than previously reported prevalence of eating disturbances among males warrants further exploration as well. Secondary analysis of new subscales on both the eating disorder and family relationship scales would benefit from reliability and validity studies. Conducting this type of methodological research on larger more systematically-gathered samples should provide important information as well. 
EATING DISORDERS: THE CORRELATION OF FAMILY RELATIONSHIPS WITH AN EATING DISORDER CONTINUUM

$$
\text { by }
$$

JANA SCHWEITZER

A thesis submitted in partial fulfillment of the requirements for the degree of

\author{
MASTER OF SCIENCE \\ in \\ PSYCHOLOGY
}

Portland State University

1988 
TO THE OFFICE OF GRADUATE STUDIES AND RESEARCH:

The members of the Committee approve the thesis of Jana Schweitzer presented July $12,1988$.

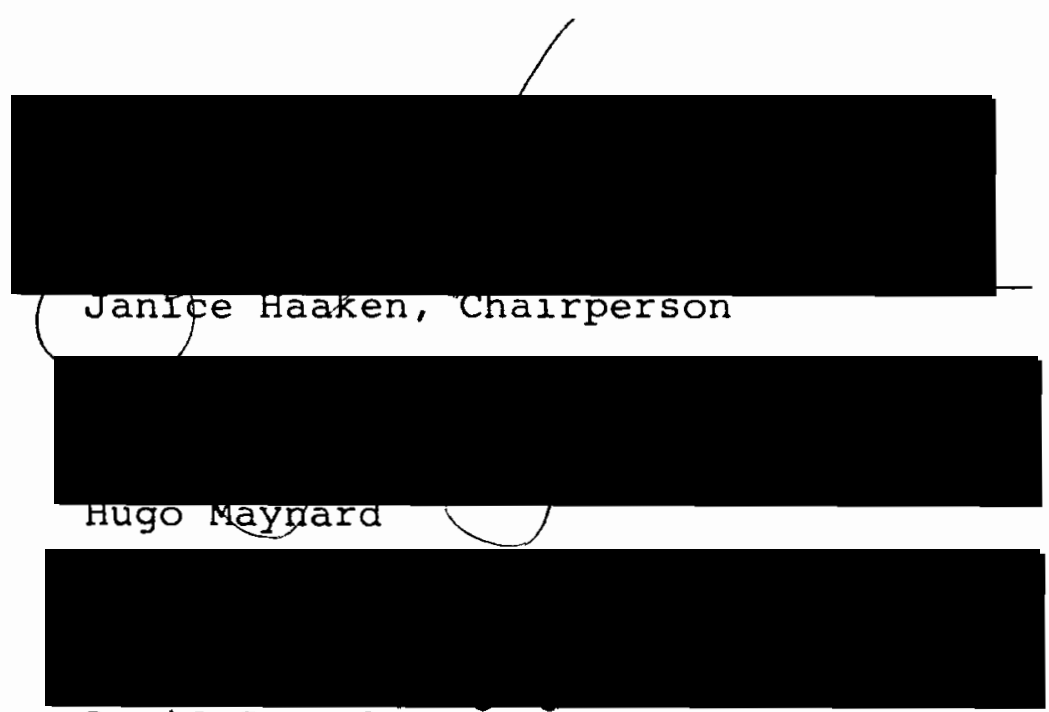

David Cressler

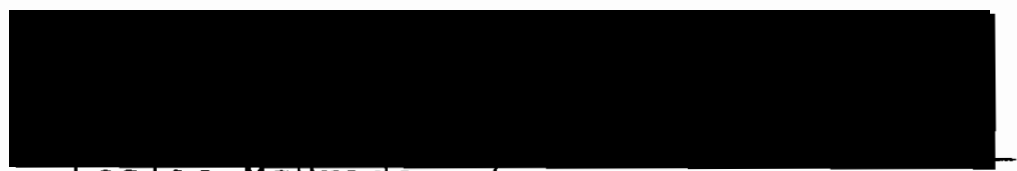

Lesire McBride

APPROVED : $A$

Rogeyf Jennings / Head, Department of Psychology 
TABLE OF CONTENTS

PAGE

LIST OF TABLES $\ldots \ldots \ldots \ldots \ldots \ldots \ldots \ldots \ldots \ldots \ldots \ldots \ldots$ v

LIST OF FIGURES $\ldots \ldots \ldots \ldots \ldots \ldots \ldots \ldots \ldots \ldots \ldots \ldots$ vii CHAPTER

I. INTRODUCTION $\ldots \ldots \ldots \ldots \ldots \ldots \ldots \ldots \ldots \ldots \ldots$

THE DISORDERS $\ldots \ldots \ldots \ldots \ldots \ldots \ldots \ldots \ldots$

ETIOLOGY $\ldots \ldots \ldots \ldots \ldots \ldots \ldots \ldots \ldots \ldots \ldots \ldots$

FAMILY INFLUENCE $\ldots \ldots \ldots \ldots \ldots \ldots \ldots$

RESEARCH DESIGN PROBLEMS .......... 10

II. PRoblem StATEMENT .................... 14

III. PROCEDURE AND METHOD ............... 17

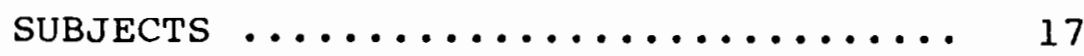

DATA-GATHERING PROCEDURE $\ldots \ldots \ldots \ldots \ldots$

SCORING PROCEDURE $\ldots \ldots \ldots \ldots \ldots \ldots \ldots 20$

STATISTICAL ANALYSES ............ 24

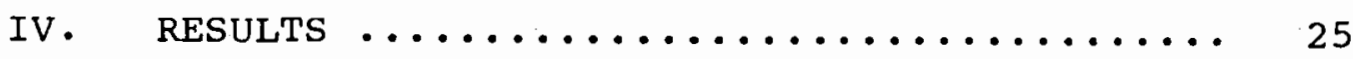

PRIMARY ANALYSIS .............. 25

MULTIPLE REGRESSION CORRELATIONS .... 28

SECONDARY ANALYSIS ............. 39

Problem $\ldots \ldots \ldots \ldots \ldots \ldots \ldots \ldots$ 
Subscale Construction and

Scoring $\ldots \ldots \ldots \ldots \ldots \ldots \ldots \ldots$ 4 41

Analysis .................. 44

Secondary Multiple Regression

Analysis ............... 45

v. DISCUSSION $\ldots \ldots \ldots \ldots \ldots \ldots \ldots \ldots \ldots \ldots \ldots$

GENERAL CONSIDERATIONS .......... 54

OVERALL OBSERVATIONS ........... 57

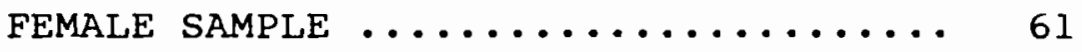

MALE SAMPLE ...................... 69

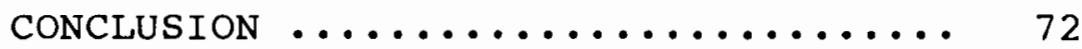

VI. SUMMARY $\ldots \ldots \ldots \ldots \ldots \ldots \ldots \ldots \ldots \ldots \ldots \ldots \ldots$

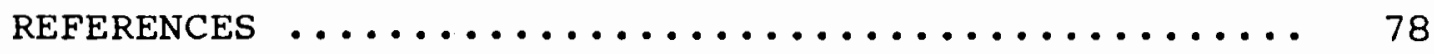

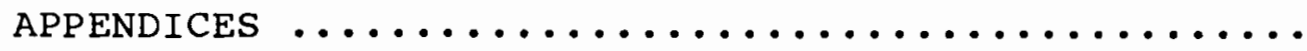

A. QUESTIONNAIRE $\ldots \ldots \ldots \ldots \ldots \ldots \ldots \ldots \ldots . \ldots \ldots$

B. SCORING FOR CUT-OFF SCORES FOR INTERMEDIATE GROUP ON EAT $\ldots \ldots \ldots \ldots \ldots \ldots \ldots \ldots \ldots \ldots$

C. PRIMARY ANALYSIS: DESCRIPTIVE STATISTICS

ON DEMOGRAPHIC AND FAMILY VARIABLES FOR

SAMPLE OVERALL AND FOR MALE AND FEMALE

SAMPLES $\ldots \ldots \ldots \ldots \ldots \ldots \ldots \ldots \ldots$

D. PRIMARY ANALYSIS: PEARSON PRODUCT MOMENT CORRELATIONS ON ALL PAIRS OF VARIABLES FOR SAMPLE OVERALL AND FOR MALE AND FEMALE SAMPLES $\ldots \ldots \ldots \ldots \ldots \ldots \ldots \ldots \ldots$ 
E. SCORING FOR EATING DISORDER SUBDIMENSIONS. 106

F. SECONDARY ANALYSIS: DESCRIPTIVE STATISTICS ON EATING DISORDER AND FAMILY SUBDIMENSIONS FOR SAMPLE OVERALL AND FOR MALE AND FEMALE

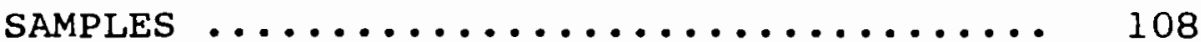

G. SECONDARY ANALYSIS: PEARSON PRODUCT MOMENT CORRELATIONS ON ALL PAIRS OF VARIABLES FOR SAMPLE OVERALL AND FOR MALE AND FEMALE SAMPLES $\ldots \ldots \ldots \ldots \ldots \ldots \ldots \ldots \ldots \ldots \ldots$ 


\section{LIST OF TABLES}

TABLE

PAGE

I. Mean, Range, and Standard Deviation for

Age and Eating Disorder Score........... 27

II. Primary Analysis: Correlations of EAT With

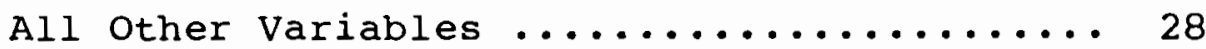

III. Multiple Regression Analyses: Relation of

Mother's Occupation, Family Leadership,

Emotional Expressiveness with Eating

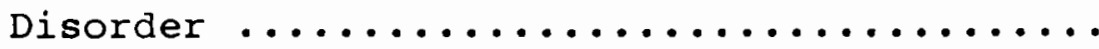

29

IV. Multiple Regression Analyses: Relation of

Family Cohesion, Leadership, and Parent-

Child Relationship With Eating Disturbances. 30

V. Primary Analysis: Correlations for Pairs of

Independent Variables Used in the Multiple

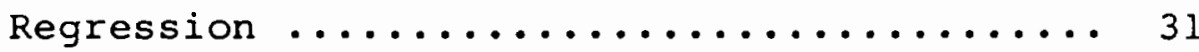

VI. Primary Analysis: Significance Levels For

Individual Variables Used in Each Multiple

Regression Analysis .................. 32

VII. Secondary Analysis: Correlations of EAT with

All other Variables ..................... 44 
VIII. Multiple Regression Analyses: Power, Control, and Needs in the Family and in the Eating Disturbance $\ldots \ldots \ldots \ldots \ldots \ldots \ldots \ldots \ldots \ldots$ 46

IX. Multiple Regression Analyses: The Relation Between the Father's Involvement and Eating Disturbance $\ldots \ldots \ldots \ldots \ldots \ldots \ldots \ldots \ldots \ldots$

X. Multiple Regression Analyses: Relation

Between Current Weight, Feelings About a Small Change in Weight, and the overall

Eating Disorder Score ............... 48

XI. Multiple Regression Analyses: The Relation

Between a Person's Pattern of Responses and Their Anorectic or Bulimic Inclinations .... 48

XII. Secondary Analysis: Correlations for Pairs of Independent Variables Used in the

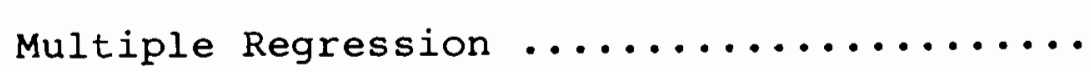

XIII. Secondary Analysis: Significance Levels for Individual Variables Used in the Multiple Regression Analyses That Utilized More Than One Variable $\ldots \ldots \ldots \ldots \ldots \ldots \ldots \ldots \ldots \ldots$ 


\section{LIST OF FIGURES}

FIGURE

PAGE

1. Percentages of eating disordered, intermediate and normal females and males .. 26 
CHAPTER I

INTRODUCTION

Anorexia nervosa and bulimia have both generated extensive interest in the last 15 years. Although anorexia was first described in 1689 by Morton and received increasing attention after the turn of the century (Sours, 1974), the increasing incidence of both eating disorders is cause for serious concern (Bruch, 1973; Johnson \& Flach, 1985). Bulimic behavior has been reported with as high a frequency of 5 to 198 in college women (Halmi, Falk, \& Schwartz, 1981), and is thought to affect between 1 and 28 of the general population (Fairburn, 1983). Anorexia is thought to require treatment in at least one out of every 155 women in affluent Western societies (Garfinkel \& Garner, 1982). Figures regarding frequency are unreliable, in part due to the secrecy of many of the afflicted people and the secrecy associated with seeking treatment--the prevalence may, in fact be higher. Both disorders are pervasive, potentially lifethreatening, and are very difficult to treat. (For a review of treatment outcome, see Bemis, 1978, and Morgan \& Russel1, 1975). 


\section{THE DISORDERS}

Anorexia nervosa and bulimia are the two main sub-classifications of eating disorders. Anorexia nervosa, or voluntary starvation, is a complex syndrome with a variety of symptoms. It is characterized by voluntary restriction of food, pursuit of thinness as pleasure in itself, food avoidance and preoccupation, hyperactivity and increased energy output, and in women, is usually accompanied by amenorrhea (Sours, 1974; DSM III). Bulimia is generally characterized by binge eating, in which large quantities of food are eaten in a short duration of time, accompanied by an awareness of this behavior as being disordered, with the fear of not being able to be able to stop; depressive moods with self-deprecating thoughts following the binge; and self-induced vomiting, use of laxatives, or fasts as a means of achieving weight control (DSM III).

Questions regarding interrelationships between these disorders have not been clarified, as bulimia has been described as both a symptom of and as a disorder separate from anorexia (Kog \& Vandereycken, 1985). For the purposes of this research, they will be viewed initially as separate disorders, i.e., different criteria will be used in judging the two disorders, to determine if family constellations lend themselves to being able to discriminate between types 
of eating disordered people.

In my experience with clients in psychotherapy, I have been struck by the frequency with which people report disturbances and discomfort with food, even where no discrete eating disorder is present. This is demonstrated in a variety of ways. Clients often describe a strong preoccupation with food, counting calories, etc., yet not to the degree of food avoidance and self-starvation. They also elaborate on feelings of being out of control around food, exercising regularly and vigorously to maintain weight, yet still within reasonable limits. Frequently described as well are feelings of wanting to be able to vomit after meals for purposes of weight control, yet holding off due to a dislike of the act of vomiting. These preoccupations may represent an intermediate group on a continuum of normal to eating disordered individuals that has not been pursued in the existing literature. Understanding this group further may clarify diagnostic categories of eating disorders as well.

\section{ETIOLOGY}

The recent increase in the prevalence of eating disorders has generated considerable interest in possible etiological factors. In the recent literature, there are a variety of attempts to explain anorexia nervosa and bulimia, ranging from biological to family systems 
explanations (Bemis, 1978; Hsu, 1983). There is a growing consensus that familial, biological, and sociocultural factors all contribute to the development of both anorexia and bulimia (Johnson \& Flach, 1985). Clinicians and researchers have increasingly studied family psychopathology, in an effort to delineate elements of family structure that are maybe causal to eating disorders (Humphrey, Apple \& Kirschenbaum, 1986). Both anorexia nervosa and bulimia appear to encompass difficulties both in the mother-child relationship (Bruch, 1973; Selvini-Palazzoli, 1978; Kalucy, Crisp, \& Harding, 1977) and in family interaction patterns and roles (Minuchin, Rosman, \& Baker, 1978).

\section{FAMILY INFLUENCE}

While the etiological role of family factors in both bulimia and anorexia nervosa has received increased research attention, results have been inconclusive. Attempts to identify typical anorectic parents and family interactions have produced inconsistent findings (Crisp, Hsu, Harding, \& Hartshorn, 1980; Kalucy, Crisp, Lacey, \& Harding, 1977). For example, Yager (1982) describes the typical anorectic parents as rigid, overprotective, extremely achievement-oriented and image-conscious parents. Mothers are described as being enmeshed (i.e.. over-involved emotionally with their children) and fathers 
as somewhat remote (i.e., emotionally distant). The family, as a whole, demonstrates poor ability to resolve conflict. However, the very diversity of patient presentation makes it difficult to argue that there is a typical family that produces that syndrome. Other studies have pointed to different family profiles, with variations in emotional involvement of the family members and in the ability to resolve conflict (Hall, 1978; Crisp, Hsu, Harding, \& Hartshorn, 1980; Kog \& Vandereycken, 1985).

Eleven investigations of anorectics have depicted mothers as dominant and intrusive while six studies failed to observe this trait. No other consistent patterns of family characteristics were seen in these studies either (reported in Bemis, 1978). Perhaps Yager (1982) presents the most accurate profile of family characteristics, reporting that research has identified a range of mother-daughter relationships extending from the overprotective to ambivalent to rejecting to "normal."

Numerous studies have focused on separation-individuation ${ }^{1}$ difficulties experienced among

${ }^{1}$ Separation-individuation refers to the early developmental process characterized by the child beginning to separate from the mother-infant dyad, and beginning to develop a sense of self with individual identity. This process of separation from parents and becoming one's own individual is also seen to occur at a more advanced level 
patients with over-involved, overprotective parents (Ordman \& Kirschenbaum, 1986). Fathers of bulimic daughters have also been described as remote, absent, powerful men from whom their daughters attempt to gain approval, and as ineffective interpersonally, playing an insignificant part of the family (Reed \& Sech, 1985). The question of whether the fathers are remote is therefore unclear if they are also reported as being overinvolved. Humphrey's (1986) findings suggest that the relationship with the father may be more important etiologically than is traditionally claimed in analytic theory. The impact of the fathers upon the development of eating disorders has not been examined as extensively as that of the mothers.

Family attributes that have been examined include expressivity of emotion, degree of chaos, presence or absence of boundaries between individuals and between generations, amount of nurturance present as perceived by the afflicted child, and cross-generational alliances. Humphrey (1986) examined the deficits in nurturance, empathy, and affective regulation on both a familial and intraphysic level as possible contributors to eating disorders using Benjamin's Structural Analysis of Social Behavior (a structural model based on scaled responses to a

in the transition from adolescence to adulthood. 
questionnaire: Benjamin, 1974). She found that bulimics did experience deficits in both parental nurturance and empathy relative to normal women, and that the deficits in perceived nurturance were stronger for bulimics than anorectics. Additionally, she found that parents of all types of eating disordered patients were viewed as more rejecting, blaming, and neglectful than were the parents of the normal controls. Hers is the only study that has approached the question of nurturance and empathy in this manner.

Kog and Vandereycken (1985) cite evidence of "marked female dominance" (p. 166) in eating disordered families, lending some support to the often-cited clinical case study literature in which the mother is described as omnipotent, a powerful woman who is both feared and identified with by the eating disordered offspring (Thoma, 1977: Chediak, 1977; Seligman, 1976; Horner, 1984). However, they also cite evidence of eating disordered families in which no dominant figure emerged. No other systematic investigations of the dimensions of maternal dominance or omnipotence are known.

A related area of interest to this author that has not been reported in the literature is the relationship of maternal employment to eating disorder presence among children. As a certain authority is derived from paid employment, the child of a working mother might identify 
with this authority and not feel compelled to try to establish his or her own authority and independence through manipulations with food. This sense of authority might be conveyed even more strongly when the mother's occupation has a higher status. Orbach (1986) pursues this concept of eating disorders as a means particularly for women to empower and establish themselves as autonomous people.

Alternatively, the mother's absence from the home as a result of her employment might be a more critical condition. Mothers are often viewed as the primary providers of nurturance in the family, so the mother's absence might become associated with a lack of nurturance as perceived by the child. Emotional response to not feeling nurtured can be quite variable. Orbach (1986) and Chernin (1985) describe the symbolic relationship between food and emotional nurturance, initially derived from the infant's experiences of being fed by their mothers. Orbach and Chernin develop a description of the way in which a preoccupation with food can be a way of managing ambivalent feelings about emotional and dependency needs. An example of this ambivalence might be a bulimic who binges in trying to soothe herself, and who then, feeling unworthy of this soothing, purges. The question of maternal employment is thus seen to have potentially varying effects upon her child's behavior around food. 
Broader family dimensions have been examined with various outcomes. Garfinkel, Garner, Rose, Darby, Brandes, O'Hanlon, \& Walsh (1983) cite findings of bulimic families demonstrating more chaos, greater conflict, less cohesion, and less communication than families of anorectics ( $p$. 822). Kog, Vertommen, \& Degroote (1985), in examining the factors of conflict behavior, degree of cohesion (i.e., support and concern among family members), degree of boundary disorganization (clarity of structure, rules, and division of responsibility), and perspectives toward autonomy in children, reported more conflict and boundary disorganization present in all types of eating disordered families than in normal controls, but did not find any difference in degree of family cohesion or enmeshment. Kog et al. (1985) also used the categories of "restricting anorectic," (i.e., a person who voluntarily restricts food intake to the point of starvation, per definition of DSM III) and "bulimic anorectic" (i.e., a person who both severely restricts food intake and also binges and purges, in contrast with a "normal weight bulimic" who binges and purges, but does not restrict food intake), rather than bulimic and anorectic, thus making a comparison with other studies of anorectics and bulimics more complicated. They found that restricting anorectics scored more similarly to normal controls on degree of conflict and disorganization present in the family than did bulimic anorectics or normal 
weight bulimics. They conclude that the "presence or absence of bulimia might be a more significant subdividing criterion than the presence or absence of weight loss" ( $p$. 240)

Kog et al. (1985) also examined the relationship between family size and eating disorders and found that the degree of conflict increased and cohesion decreased with the increase in family size. They also examined the relationship of the differing ages of the patients when reporting to their recollections of family interactions, and found that as the child grew older, she would report less conflict and disorganization, and more cohesion, and also that the child's report at older ages was more similar to the parent's report. These findings illuminate some of the significant problems that arise with studying family relationships.

\section{RESEARCH DESIGN PROBLEMS}

Overall, a wide variety of research methods have been used in the study of eating disorders, making comparisons across studies difficult. Kog and Vandereycken (1985) performed a careful systematic overview of the research literature, and provide a useful discussion of the range of methodological approaches. Control group studies are a more recent and still fairly infrequent phenomenon, but are much needed in order to begin to delineate factors that 
differentiate eating disordered and normal families, something that case study research is unable to do. These control group studies have used various measurement tools, have asked somewhat different questions, or have used varied enough clinical samples that drawing conclusions is difficult.

As noted earlier, diagnostic criteria are not sufficiently clear, further confounding the picture. Some family descriptions are provided by clinical impressions stemming from therapy with one or a few cases over time; others are gathered from observations of family interactions; others are provided by self-report retrospective questionnaires completed either by the patient alone or by all the family members, although the latter are quite scarce. More precise measurement tools and more systematic research procedures would assist in furthering the research in this area.

Additional questions that have been raised in the literature involve demographic variables. Anorexia is predominantly thought to occur in the "upper middle," "professional," and "managerial" classes (Morgan \& Russell, 1975; Crisp, Hsu, Harding, \& Hartshorn, 1980; Crisp, Palmer, \& Kalucy, 1976; Hall, 1978), although there are a few studies that cite cases among working-class women (Crisp et al., op cit; Crisp, 1983; Kalucy, Crisp, \& Harding, 1977). It is unclear whether this skew reflects 
actual class differences or a difference in the willingness of families of varying class backgrounds to seek psychiatric help (Morgan \& Russell, 1975). As many of the studies have used patient samples from psychiatric teaching hospitals specializing in the treatment of anorexia, there may be selection influences resulting in biased samples. It is also possible that differing family characteristics might be present in those families affected by anorexia who either do not seek treatment at all, or who seek only medical, but not psychiatric, treatment. Kog and Vandereycken (1985) state that "over-representation of the higher social class...has been validated by well controlled research" (p. 161). However, they then proceed to describe some variability among the different types of eating disorders, although these indicate conflicting results as to whether bulimics tend to come from a higher or lower social class than do anorectics. They conclude that the different locales of these studies or different diagnostic criteria might account for the discrepancies seen.

Eating disorders are also seen to predominantly affect women (Ross, 1977; Sours, 1974; Seligman, 1976; Pope, Hudson, \& Jonas, 1986). Various attempts have been made at a socio-cultural explanation for this skew (Orbach, 1986; Chernin, 1985; Crisp, 1983). While male bulimics and anorectics have been studied (Pope et al. 1986; Beumont, Beardwood, \& Russell, 1972; Crisp \& Burns, 1983), minimal 
information regarding family background has resulted. Studies have yielded conflicting results regarding ways in which eating disordered men may differ from eating disordered women.

An overview of the existing research on family dynamics in eating disordered families suggests the need for research where appropriate control groups, large samples, and a systematic data-gathering process are used. Appropriate group comparisons include intergroup comparisons between eating disordered groups, normal controls, and/or various psychiatric groups, as well as intragroup comparisons between various eating disordered subgroups (Kog and Vandereycken, 1985). Research conducted incorporating these parameters could assist in determining what types of causal factors might be present in the families in which various types of eating disorders are present, and might offer insight specifically into the question of why an eating disorder (or even a particular one) emerges rather than some other clinical condition. In other words, can necessary preconditions be discriminated from those that are present but nonessential? Yager (1982) observed that many of the earlier-described gamut of parent-child relationships are seen in families with and without evidence of ensuing psychopathology, and raised the question of why some families yield an eating disordered member and others do not. 
CHAPTER II

\section{PROBLEM STATEMENT}

Given the increasing prevalence and difficulty in successfully treating eating disorders, primary prevention emerges as an important area to pursue. One of the keys in preventing the occurrence of these disorders is to understand possible causal family variables, thus enabling one to ascertain predictive factors. In analyzing a variety of family factors, and determining weighted combinations which are correlated with anorexia or bulimia, it was hoped that this study would offer a means to begin to suggest possible primary preventive measures.

In addition to examining family factors associated with eating disorders, this study attempted to ascertain if, in fact, intermediate subgroups could be delineated in the general population and whether family factors could be identified that could contribute to the development of intermediate subgroups.

As the sample used in this study was drawn from a broad college population, it provided an opportunity to further examine the question of the correlation between social class and eating disorders, potentially yielding 
information about subgroups of eating disorders. It was also an opportunity to gather more data regarding the incidence of eating disorders in men and women.

Finally, as the existing family research is broad and not always systematic, the current study attempted to focus and coordinate the research direction by systematically exploring the above issues using a methodological tool that was initially conjectured to be comprehensive and that could easily be applied to other samples.

The major goals of this study were:

1. To examine demographic aspects of the sample;

2. To look for the presence of identifiable clinical subgroups who showed some characteristics of an eating disorder but not the full syndrome; and

3. To examine family constellations, interaction patterns, and parent-child relationships to determine any factors that might be correlated with an eating disorder or clinical subgroup.

Specific questions to be explored included:

1. What is the incidence of eating disorders in this college sample, compared with other similar samples? The incidence in college samples has been cited with a range of 5.3 to $19 \%$ (Halmi, Falk, \& Schwartz, 1981; Pyle \& Mitchell, 1986) •

2. What is the incidence of anorexia and bulimia in men and women in this sample, given that most previous 
studies have not studied both genders simultaneously?

3. Is there a correlation between the type of eating disorder and socio-economic status of family members?

4. Does a correlation exist between specific family variables and the classification and subsequent placement of respondents on a continuum ranging from eating-disordered to normal?

5. What is the association between maternal employment and the development of an eating disorder in the child?

6. What is the association between severity of an eating disorder and degree of family control?

7. What is the association between degree of family chaos and severity of eating disorder?

8. What is the association between family conflict and severity of an eating disorder? Do other significant family factors combine with the presence of conflict and correlate even more strongly with the presence of an eating disorder?

9. Are the parents of eating disordered subjects overly intrusive or under-involved?

10. Is the relationship with the mother or the father more strongly correlated with the presence of an eating disorder?

11. Is the issue of perceived maternal or paternal power important in relation to the presence of an eating disorder? 
CHAPTER III

PROCEDURE AND METHOD

SUBJECTS

Participants in the study consisted of 170 lower division undergraduate students at an urban university, drawn from four undergraduate Psychology courses. A pilot study was initially conducted using 20 lower division undergraduate students, to determine any problems there were in the format or administration of the questionnaire. Some modifications were made, including the underlining of some key items, and the deletion of one section of the questionnaire as it was found to be too confusing for the subjects. The final questionnaire contained five sections. The subjects were selected by volunteering to participate in the study. Clinically diagnosed subjects were not used, due to both the difficulty in gaining access to this population and constraints on generalizing from a clinical population. It was hoped that using a college population would provide a means of assessing the prevalence of sub-clinical eating disorders as well. 
DATA-GATHERING PROCEDURE

The subjects were given a 155 -item self-report questionnaire subdivided into 5 sections (see Appendix A). In the first two sections, general demographic information and nutrition history were ascertained. These included questions regarding the socio-economic, educational, and professional statuses of the subjects and their parents, as well as general health and nutrition questions to provide a broad sense of the person's relationship with food. In the two family relationship sections, specific family variables examined included presence of conflict between parents, and between each parent and the eating disordered person; degree of emotional expressivity, perceived empathy and nurturance; degree of cohesion from enmeshed to distant; parental roles in the family; and the quality of the relationship of the child toward each parent to determine degree of identification with, or ambivalence or hostility towards each parent. The final section asked specific questions regarding the presence, tendency towards, or absence of an eating disorder.

This questionnaire was compiled from the Self-Report Family Instrument (Beavers, Hampson, \& Hulgus, 1985), Child's Attitude Toward Father and Mother (Hudson, 1982), Diagnostic Survey for Eating Disorders (Johnson, 1985), and The Eating Attitudes Test (Garner \& Garfinkel, 1979), with 
broad nutrition questions created by the author following ideas generated by the Nutrition Attitude Survey (Hollis, Carmody, Connor, Fey, \& Matarazzo, 1986). Except for the demographic questions, all five sections involved scaled responses and had known reliability and validity indices computed.

Subjects were recruited by the experimenter contacting them in their undergraduate classes. They were told that they were being invited to participate in a study examining how current health and nutrition lifestyles are connected to relationship patterns in the families in which they were raised. They were asked to take the questionnaire during class time. The questionnaire was group administered, with no limitation on time for completion of the questions. The investigator was present during all administrations of the questionnaire, and was available to answer any questions or concerns that may arise. As no follow-up information was gathered, the subjects participated anonymously, with no further contact after survey completion. Treatment of subjects was in accordance with the ethical standards of the APA and following Human Subjects Review Committee guidelines.

SCORING PROCEDURE

Variables on the questionnaire sections are described and scored as follows: 
DIV and DEATH refer to presence of divorce or death among the parents. A score of $0=$ absent, $1=$ present. FOCC and MOCC refer to father's and mother's occupation. These involved scoring occupation and income, each on a scale of 1 to 10 , and summing them. The range for income was a score of 1 for income of $\$ 0-5,000$, to a score of 10 for income of $\$ 75,000$ and greater. On the occupation scale, an unskilled employee was given a score of 1, a semiskilled employee a 2, a skilled manual employee a 3 , clerical or sales worker a 4, administrative personnel a 6 , a business manager of large concern an 8, and higher executive a 10. A score of zero was given for an indication that a person had never worked in paid employment. Scores were deleted when the information was not provided.

FEDUC and MEDUC refer to father's and mother's education. A score of 3 was assigned for schooling up to and through completion of grade 7,4 for grade 8,5 for completion of high school, 6 for 2 years of college or trade school, 8 for a Bachelor's degree, 9 for a Master's, and 10 for a $\mathrm{Ph} . \mathrm{D}$.

CAF and CAM refer to the Child's Attitude Toward Father and Mother scale (Hudson, 1982). These were scored as indicated by their author. Although normative data on these scales are not known, a score above 30 indicates that the respondent has a clinically significant problem in the parent-child relationship. 
COHESION, HEALTH, CONFLICT, LEADER, COMM, and EMOTE are the 6 subscales derived from the Self-Report Family Instrument (Beavers, et al., 1985). All were scored on a scale of 1 to 5 . COHESION refers to level of family cohesion, a subscale based on 5 items, with a low score indicating an excessively cohesive family in which family members turned much more to one another than to the outside world for their satisfaction. A high score indicates a very noncohesive family. HEALTH refers to family health, and is based on 8 items. A low score indicates a healthy family, a high score an unhealthy family characterized by lack of mutual respect, lack of happiness, and lack of appreciation and support for one another. CONFLICT refers to family conflict ( 12 items), with a low score indicating lack of conflict, and a high score, the strong presence of conflict. LEADER refers to directive leadership (3 items), with a low score indicating strong leadership present, and a high score, the lack of leadership. COMM refers to family communication ( 4 items), with a low score indicating good, clear communication, and a high score the lack thereof. EMOTE ( 5 items) is a subdimension that was not empirically defined by the authors of the instrument. Inspection of the questions reveals that they are all concerned with the dimension of emotional expressivity (i.e., "Family members easily expressed warmth and caring towards each other"), so this subscale was cautiously 
treated as measuring that variable. A low score was construed to indicate that the family was emotionally expressive; a high score that expression of emotion was absent. Normative data are not available on the SFI.

Subjects were divided into three criterion groups of eating disordered, intermediate, and normal control based on their scaled responses to questions in the second health and nutrition section (section 5, the EAT). The purpose of the first health and nutrition history section was to be able to place people broadly into categories of eating disorder or control, to gather data that may illuminate related aspects of their lifestyle $(\mathrm{e} . \mathrm{g} .$, whether they needed to maintain a specific weight for their occupation), and to ease the discomfort of answering more sensitive detailed questions concerning specific behaviors with food. Scoring for screening into the discrete categories of presence or absence of eating disorders on section 5 was done following guidelines provided by Garner and Garfinkel (1979). They proposed a cut-off score on the EAT of 30 as the division between anorectic and nonanorectic subjects. Button and Whitehouse (1981), in further exploring the use of the EAT as a screening procedure, concluded that a high score may not be diagnostic of anorexia nervosa, but certainly indicates the degree of concern about food intake and weight. 
A minimum cut-off score was determined by this author to separate "normals," people who were disturbed very little in their relationship to food and body image, from the intermediate group in which increasing concerns were seen in these areas. A total of 18 questions on the EAT such as "Become anxious prior to eating," "Feel extremely guilty after eating," "Am preoccupied with the thought of having fat on my body," and "Give too much time and thought to food," were tabulated in the "sometimes" or "often" to "very often" range. (See Appendix B for details of scoring). Suming the lowest score for these 18 questions yielded a minimum score of 11.5 for placement into this intermediate group.

Bulimic symptomatology was tentatively ascertained through the use of portions of the DSED (Johnson, 1985). These are found in section 2 , and in questions 40-44 in section 5. The entire questionnaire was not used, as it was felt to be too detailed and potentially threatening to the sample. Efforts to distinguish anorectic from bulimic subjects thus could not be attempted.

\section{STATISTICAL ANALYSES}

In the initial design of the study, after subdivision into the three criterion groups, the plan was to examine the relative weighting of the family measures in association with the three groups. However this would 
require a comparable number of subjects within each group. As the results of other research indicates that college samples are likely to yield 5.3 to 198 eating disordered people (see Problem Statement), I recognized that it would be highly unlikely to achieve three groups of comparable size. It was decided to use a multiple regression analysis, as a way to examine the relationship of various measures simultaneously to the degree of eating disorder present. As a multiple regression analysis would use the raw scores on the eating disorder scale, this would circumvent the problem of number of subjects in discrete criterion groups, and would provide information about the continuum of eating disorder scores. 
CHAPTER IV

\section{RESULTS}

\section{PRIMARY ANALYSIS}

Descriptive statistics were obtained on the sample overall, and for men and women separately. Mean, range, and standard deviation for age and eating disorder score of the samples are given in Table I. The delineation into criterion groups of eating disordered (EAT > 30), Intermediate $(30 \geq \mathrm{EAT} \geq 11.5)$, and normal control (11.5>EAT) is presented in Figure 1.

Complete descriptive statistics on demographic and family relationship variables are in Appendix C. For a description of the variables and scoring methods, refer to Procedure and Methods section. The mean and standard deviation for age were 25.101 years \pm 8.033 years, suggesting that eating disorders do not affect only young people. The only variables found to be particularly problematic for the subjects to report were MOCC and FOCC: $25 \%$ of the subjects were not able to answer these questions. The range of occupation and income for parents was broad, encompassing all socio-economic strata (limitations of the socio-economic measures are discussed later). The mean occupational score for the father was 


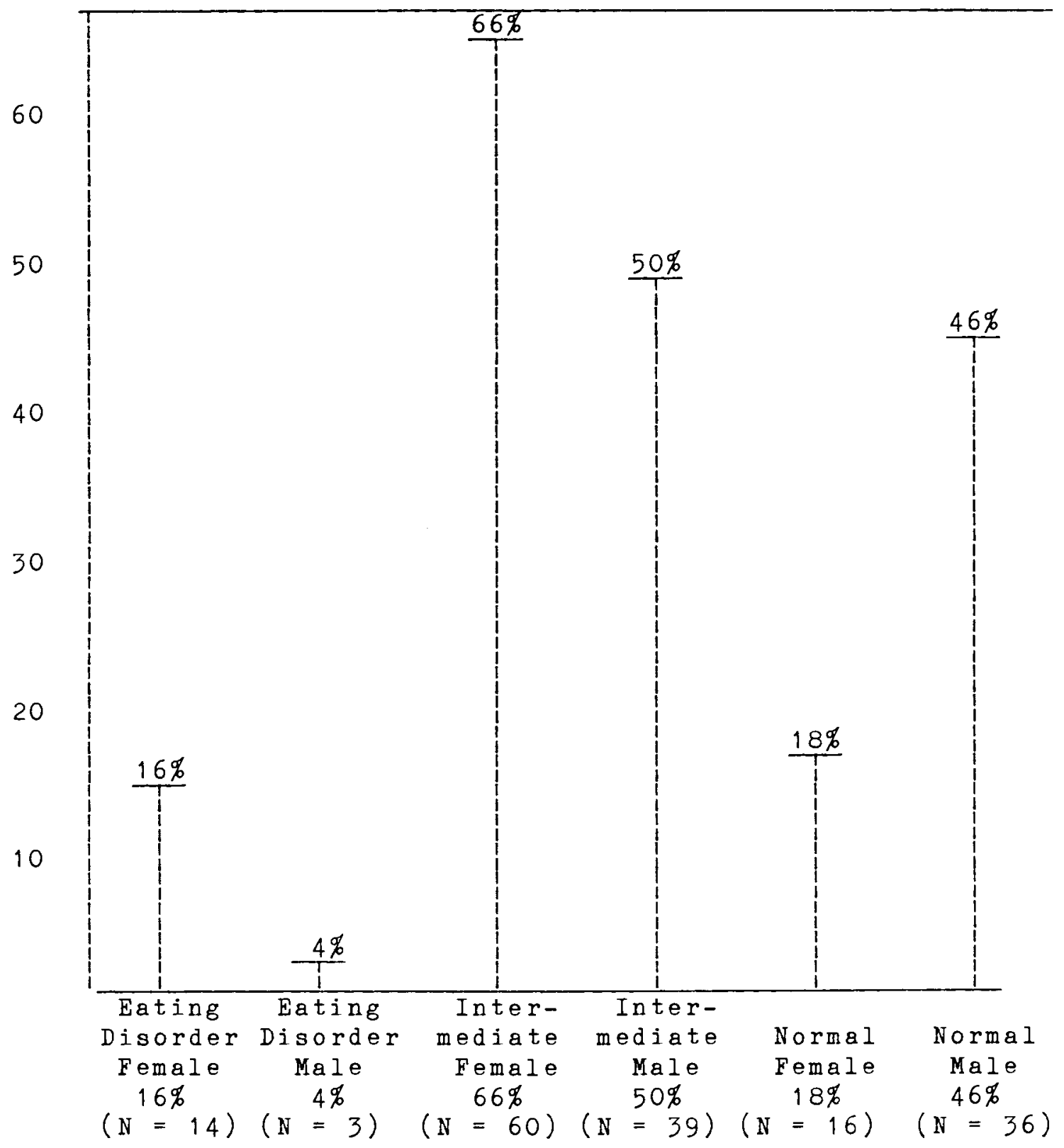

Figure 1. Percentages of eating disordered, intermediate and normal females and males. 
$14.291 \pm 4.108$, indicating a middle-class SES. The mother's occupational score ranged from never having worked in paid employment to higher executive, with a mean score of $8.616 \pm 5.088$, the lower mean score reflecting the weighting of women who hadn't worked outside the home.

Pearson product moment correlations were computed for all pairs of variables. A complete table of the correlation matrix for the overall sample and for men and women separately appears in Appendix D. Table II presents the correlations for all the variables with the eating disorder score.

\section{TABLE I}

MEAN, RANGE, AND STANDARD DEVIATION FOR AGE AND EATING DISORDER SCORE

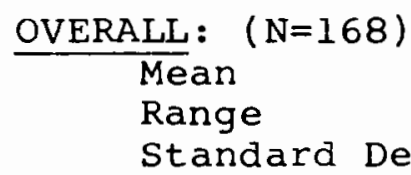

Standard Deviation

MALE: $\quad(N=78)$

Mean

Range

Standard Deviation

FEMALE : $\quad(\mathrm{N}=90)$

Mean

Range

Standard Deviation
AGE
$2 \frac{10101}{17-57}$
8.033

25.115

18-57

8.210

25.089

17-49

7.923

$$
\begin{array}{r}
\frac{E A T}{16.993} \\
4.5-6.5 \\
10.089
\end{array}
$$

$$
\begin{array}{r}
13.827 \\
4.5-46 \\
7.582
\end{array}
$$

19.737

$4 \cdot 5-67.5$

11.174 
TABLE II

PRIMARY ANALYSIS:

CORRELATIONS OF EAT WITH ALL OTHER VARIABLES

VARIABLE
SEX
AGE
DIV
DEATH
FOCC
MOCC
FEDUC
MEDUC
CAF
CAM
COHESION
HEALTH
CONFLICT
LEADER
COMM
EMOTE
* P<. 05

\begin{tabular}{|c|c|c|}
\hline$N=168$ & $\mathrm{~N}=78$ & $\mathrm{~N}=90$ \\
\hline OVERALL & MALE & FEMALE \\
\hline $.293^{\star} \star$ & & \\
\hline-.168 & -.206 & -.163 \\
\hline .076 & -.050 & .074 \\
\hline-.007 & -.041 & .022 \\
\hline .061 & .003 & .136 \\
\hline $.151 *$ & -.023 & $.273^{\star} \star$ \\
\hline .091 & -.066 & .167 \\
\hline .068 & .118 & .010 \\
\hline $.238^{\star}$ & .133 & $.259 \star$ \\
\hline .111 & .036 & .143 \\
\hline .075 & -.135 & .173 \\
\hline $.170^{\star}$ & .069 & .189 \\
\hline $.291 \star \star$ & . 249* & 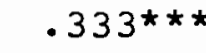 \\
\hline .147 & .003 & .192 \\
\hline-.091 & .004 & -.184 \\
\hline .079 & -.054 & .117 \\
\hline .0 & & 001 \\
\hline
\end{tabular}

MULTIPLE REGRESSION CORRELATIONS

A multiple regression analysis was conducted to examine the effects of several of the variables concurrently in relationship to the eating disorder score. As the number of subjects in the three criterion groups of eating disordered, intermediate, and normal was so disparate, raw scores on the EAT rather than distinct groups were used in the multiple regression analyses. Summary results of these analyses are given in Tables III and IV, along with a statement of each hypothesis. 
TABLE III

MULTIPLE REGRESSION ANALYSES: RELATION OF MOTHER'S OCCUPATION, FAMILY LEADERSHIP, EMOTIONAL EXPRESSIVENESS WITH EATING DISORDER

$\underline{\text { SAMPLE }} \underline{\mathrm{N}} \quad \underline{\text { F-RATIO }} \underline{\mathrm{P}} \underline{\underline{\text { SQUARED }}}$

1) $\mathrm{EAT}=$ LEADER + MOCC

Hypothesis: A chaotic, leaderless family with the mother working outside the home could be associated with an increased disturbance with food.

$\begin{array}{lrrrr}\text { Overall } & 125 & 3.440 & 0.035 & .053 \\ \text { Male } & 58 & 0.015 & 0.985 & .001 \\ \text { Female } & 67 & 4.665 & 0.013 & .127\end{array}$

2) EAT $=$ MOCC + LEADER + EMOTE

Hypothesis: An overly controlled family environment with a lack of emotional gratification and the mother working outside the home could be associated with an increased eating disturbance.
overall
125
2.276
0.083
.053
Male
58
0.215
0.885
.012
Female
67
3.113
0.032
.129

3) $\mathrm{EAT}=\mathrm{MOCC}+\mathrm{EMOTE}$

Hypothesis: Mother working and an emotionally deprived family could be associated with an increased eating disturbance.
Overall
125
1.525
0.222
.024
Male
58
0.292
0.748
.011
Female
67
2.909
0.062
.083

4) $\mathrm{EAT}=\mathrm{MOCC}+\mathrm{CAM}$

Hypothesis: Mother working, child experiencing problems in the relationship with the mother could be associated with an increased eating disturbance.
Overall
125
1.700
0.187
0.021
0.979
.027
Male
58
67
2.897
0.062
.001
.083

5) $\mathrm{EAT}=$ LEADER + EMOTE

Hypothesis: An emotionally remote, nonexpressive, highly controlled family could be associated with an increased eating disturbance.
Overall
168
2.029
0.135
.024
Male
78
0.116
0.891
.003
Female
90
2.021
0.139
.044 


\begin{abstract}
TABLE IV
MULTIPLE REGRESSION ANALYSES: RELATION OF FAMILY COHESION, LEADERSHIP, AND PARENT-CHILD RELATIONSHIP WITH EATING DISTURBANCES
\end{abstract}

SAMPLE $\underline{N}$ F-RATIO $\underline{\mathrm{P}}$ MULTIPLE R

1) $\mathrm{EAT}=\mathrm{CAF}+\mathrm{CONFLICT}$

Hypothesis: A conflicted family environment in which the child experienced problems with their father could be associated with an increase in eating disturbances.

$\begin{array}{lrlll}\text { Overall } & 162 & 9.671 & 0.000 & .108 \\ \text { Male } & 73 & 2.794 & 0.068 & .074 \\ \text { Female } & 89 & 6.361 & 0.003 & .129\end{array}$

2) $\quad$ EAT = CONFLICT + CAF + LEADER

Hypothesis: A highly conflicted, overly controlled family in which the child had problems with the father could be associated with increased eating disturbances.

$\begin{array}{lrlll}\text { Overall } & 162 & 6.614 & 0.000 & .112 \\ \text { Male } & 73 & 2.041 & 0.116 & .082 \\ \text { Female } & 89 & 4.492 & 0.006 & .137\end{array}$

3) EAT = CONFLICT + CAF + LEADER + COHESION

Hypothesis: A highly conflicted, chaotic family in which problems were experienced with a remote, distant father could be associated with increased eating disturbances.
Overall
162
5.590
0.000
.125
Male
73
2.513
0.050
.129
Female
89
3.471
0.011
.142

4) EAT $=$ CAM + CONFLICT

Hypothesis: A conflicted family environment in which the child experienced problems with the mother could be associated with increased eating disturbance.

$\begin{array}{lrlll}\text { Overall } & 168 & 7.630 & 0.001 & .085 \\ \text { Male } & 78 & 2.484 & 0.090 & .062 \\ \text { Female } & 90 & 5.508 & 0.006 & .112\end{array}$

5) EAT $=$ CONELICT + COHESION + CAM

Hypothesis: A highly conflicted family environment in which the mother was overly involved and viewed negatively could be associated with increased eating disturbance.

$\begin{array}{lrrrr}\text { Overall } & 168 & 5.280 & 0.002 & .088 \\ \text { Male } & 78 & 3.082 & 0.033 & .111 \\ \text { Female } & 90 & 3.631 & 0.016 & .112\end{array}$


Table $V$ presents the correlation for each pair of independent variables used in the multiple regression to ascertain any possible redundancy between those variables that might be reflected in the multiple regression analysis. If two variables are highly correlated, i.e., redundant, that indicates that no independent contribution that one variable makes is completely distinct from the other. As the variables in this study were not measured independently, it is not possible to explain the degree of correlation between any two of them. A high correlation may suggest that both variables are measuring one powerful measure that has not been identified. A multiple regression analysis only provides information regarding the relative strength of contributions of variables, with no explanation for the particular findings.

\section{TABLE V}

PRIMARY ANALYSIS: CORRELATIONS FOR PAIRS OF INDEPENDENT VARIABLES USED IN THE MULTIPLE REGRESSION

\begin{tabular}{|c|c|c|c|}
\hline VARIABLE & OVERALL & MALE & FEMALE \\
\hline$\overline{\mathrm{MOCC}}+\mathrm{CAM}$ & -.004 & $\overline{-.092}$ & .058 \\
\hline LEADER + MOCC & .163 & -.073 & .369 \\
\hline MOCC + EMOTE & .117 & .049 & .161 \\
\hline LEADER + EMOTE & .220 & .277 & .164 \\
\hline CAF + CONFLICT & .282 & .199 & .324 \\
\hline CAM + CONFLICT & .372 & .144 & .521 \\
\hline CAF + LEADER & .197 & .208 & .182 \\
\hline CONFLICT + LEADER & .270 & .263 & .283 \\
\hline CONFLICT + COHESION & .423 & .243 & .533 \\
\hline CAF + COHESION & .376 & .310 & .410 \\
\hline LEADER + COHESION & .245 & .220 & .263 \\
\hline CAM + COHESION & .473 & .432 & .501 \\
\hline
\end{tabular}


Table VI presents the significance levels for the individual variables used in each multiple regression analysis. This provides further information regarding the relative contribution of each variable, clarifying which variable(s) may be contributing most of the information within the analysis and therefore could be seen to be superceding the other variables.

\section{TABLE VI}

PRIMARY ANALYSIS: SIGNIFICANCE LEVELS FOR INDIVIDUAL VARIABLES USED IN EACH MULTIPLE REGRESSION ANALYSIS

1) $\mathrm{EAT}=$ LEADER + MOCC OVERALL VARIABLE LEADER MOCC $\underline{\underline{P(2 \operatorname{tail})}} \quad .050 \quad .173$ \begin{tabular}{cccc}
\multicolumn{2}{c}{ MALE } & \multicolumn{2}{c}{ FEMALE } \\
LEADER & MOCC & LEADER & MOCC \\
.958 & .871 & .054 & .152
\end{tabular}

2) $\mathrm{EAT}=$ MOCC + LEADER + EMOTE OVERALL MALE FEMALE VARIABLE MOCC LEAD EMOTE MOCC LEAD EMOTE MOCC LEAD EMOTE \begin{tabular}{lllllllllll}
\hline $\mathrm{P}(2 \mathrm{tail})$ & .175 & .056 & .947 & .916 & .790 & .436 & .163 & .074 & .716
\end{tabular}

3) $\mathrm{EAT}=\mathrm{MOCC}+\mathrm{EMOTE}$ OVERALL VARIABLE MOCC EMOTE MOCC EMOTE MOCC EMOTE $\begin{array}{lllllll}\underline{\mathrm{P}(2 \operatorname{tai} 1)} & .106 & .664 & .895 & .459 & .037 & .439\end{array}$

4) $\mathrm{EAT}=\mathrm{MOCC}+\mathrm{CAM}$

OVERALL \begin{tabular}{lcc}
$\frac{\text { VARIABLE }}{\mathrm{P}(2 \text { tail })}$ & MOCC & CAM \\
\hline 5) & EAT $=$ & LEADER + EMOTE \\
OVERALL & .467
\end{tabular} VARIABLE LEADER EMOTE LEADER EMOTE LEADER EMOTE \begin{tabular}{lllllll}
\hline $\mathrm{P}(2$ tail $)$ & .085 & .537 & .916 & .633 & .098 & .411
\end{tabular}

6) $\mathrm{EAT}=\mathrm{CAF}+$ CONFLICT OVERALL MALE MOCC CAM MOCC CAM $.859 \quad .907 \quad .029 \quad .447$

\begin{tabular}{lcccccc} 
& \multicolumn{2}{c}{ OVERALL } & \multicolumn{2}{c}{ MALE } & \multicolumn{2}{c}{ FEMALE } \\
VARIABLE & CAF & CONFLICT & CAF & CONFLICT & CAF & CONFLICT \\
\hline $\mathrm{P}(2$ tail $)$ & .030 & .003 & .469 & .043 & .107 & .015
\end{tabular}


Table VI (continued)

7) $\mathrm{EAT}=$ CONFLICT + CAF + LEADER

OVERALL

MALE FEMALE

VARIABLE CONF CAF LEAD CONF CAF LEAD CONF CAF LEAD $\begin{array}{lllllllllllll}\overline{\mathrm{P}(2 \mathrm{tail})} & .006 & .040 & .458 & .034 & .403 & .453 & .033 & .128 & .378\end{array}$

8) EAT = CONFLICT + CAF + LEADER + COHESION OVERALL MALE

FEMALE

VARIABLE

CONF CAF LEAD COH CONF CAF LEAD COH CONF CAF LEAD COH $\begin{array}{llllllllllll}\mathrm{P}(2 \mathrm{tail}) & \\ .002 & .016 & .355 & .128 & .018 & .187 & .596 & .059 & .027 & .099 & .338 & .486\end{array}$

9) $\mathrm{EAT}=\mathrm{CAM}+$ CONFLICT OVERALL

\begin{tabular}{lccccrc} 
VARIABLE & CAM & CONFLICT & CAM & CONFLICT & CAM & CONFLICT \\
\hline $\mathrm{P}(2$ tail $)$ & .965 & .000 & .997 & .031 & .722 & .003
\end{tabular}

10) EAT $=$ CONFLICT + COHESION + CAM

OVERALL MALE

FEMALE

VARIABLE CONF COH CAM CONF COH CAM CONF COH CAM $\begin{array}{llllllllllll}\mathrm{P}(2 \operatorname{tail}) & .000 & .434 & .737 & .011 & .047 & .405 & .007 & .951 & .722\end{array}$

Table III includes the hypotheses related to mother's occupation, presence of leadership in the family, emotional expressiveness of the family, and their relationship to the degree of eating disorder present as measured by the EAT. MOCC was correlated significantly with EAT in the sample overall $(r=.151, p<.05)$ and the female sample $(r=.273$, $\mathrm{p}<.01)$. This variable was combined with LEADER, examining the hypothesis that a person would be likely to demonstrate an increased disturbance with food when having experienced a chaotic, leaderless family with the mother working outside the home. Although the results remained significant for the overall sample and for the female sample, the contribution of MOCC was no longer significant, 
being outweighed by the contribution of the leadership variable (refer to Table III for significance levels). The correlation of LEADER with MOCC for the female sample was significant $(r=.369, p<.011)$, indicating a redundancy of information confirming these findings: the higher the mother's occupational score, the less leadership was perceived in these families.

The EMOTE variable was then added in, examining the hypothesis that an overly controlled family environment with a lack of emotional gratification and the mother working outside the home could contribute to an increased eating disorder score in the offspring. This multiple regression (MOCC + LEADER + EMOTE) was significant only for female subjects $(p=.032)$, and again, the leadership dimension outweighed the others and was the only contributing variable that was nearly significant $(p=.074)$. This variable was significant in the direction towards a chaotic family environment, and the dimension of emotional gratification added nothing significant predictively •

Examining MOCC and EMOTE together (hypothesis: mother working and an emotionally deprived family could contribute to an increased EAT) was found to be nearly significant for women only $(p=.062)$, with MOCC plus CAM tested together (hypothesis: mother working, child experiencing problems in their relationship with the mother could contribute to an increased eating disorder) yielded similar results: near 
significance $(p=.062)$ for women only, with MOCC the significant variable $(p=.029)$ outweighing the relationship problems with the mother.

Table IV presents the results of the multiple regression analyses concerning conflict in the family, problems in the relationship with each parent, the presence of leadership and cohesion in the family, and their relationship to eating disturbances. CONFLICT was correlated significantly with EAT in the overall sample $(r=.291, p<.01)$, the male sample $(r=.249, p<.05)$, and the female sample $(r=.333, p<.001)$. CAF was correlated significantly with EAT in the overall sample $(r=.238$, $p<.05)$, and the female sample $(r=.259, p<.05)$. Combining CONFLICT with CAF (hypothesis: a conflicted family environment in which the child experienced problems with their father could contribute to an increase in eating disturbances) yielded significant results for the sample overall $(p=.000 x)$ and for the female sample $(p=.003)$, and nearly significant results for the male sample $(p=.068)$. CONFLICT and CAF both were significant contributing variables for the overall sample, but when the sample was divided by gender, CAF no longer made a significant contribution, being outweighed by the degree of conflict present. The correlation of CAF with CONFLICT was .282 for the overall sample and .324 for the female sample, suggesting a significant redundancy between these 
variables. This would account for the reduction of contribution of CAF when combined with CONFLICT for the female sample.

Adding LEADER in with CONFLICT and CAF (hypothesis: a highly conflicted, overly controlled family in which the child had problems with the father could contribute to an increased eating disorder, with the child rebelling against that environment through their manipulations with food) yielded significant results for the overall sample $(p=.000 x)$ and for the female sample $(p=.006)$. The leadership dimension was positively correlated with the other variables, indicating that the family environment was chaotic rather than overly controlled. Additionally, the leadership variable did not make a significant contribution to the information that was provided by CONFLICT and CAF in the earlier multiple regression analysis.

The variable of family cohesion was then added in to the above equation (CONFLICT + CAF + LEADER + COHESION), testing the hypothesis that a highly conflicted, chaotic family in which problems were experienced with a remote distant father could contribute to increased disturbances with food and body image. The COHESION dimension was found to be negatively correlated with the other variables, indicating that the family environment was one of excessive cohesion rather than remoteness. For both the overall and female samples, the multiple regression was significant 
$(p=.000 x$ and $p=.011$, respectively), and neither leadership nor cohesion added significant information. For the male sample ( $p=.05$ for the regression analysis), COHESION provided an almost significant contribution $(p=.059)$ along with CONFLICT $(p=.018)$, and CAF and LEADER adding no new information.

The correlation of CONFLICT with COHESION was very high for the overall sample $(r=.423)$ and for the female sample $(r=.533)$, while for the male sample, $r=.243$. This suggests that for the women and the sample overall, the more conflict present in the family, the less cohesion and family involvement seen, with these dimensions being nonseparable. The smaller correlation for the men suggests that conflict and level of involvement among family members are less redundant, and that the degree of cohesion in the family is a variable with a more significant independent contribution for the men.

The correlations of CAF with COHESION were significant for all samples (overall $\mathrm{r}=.376 ; \mathrm{r}$ male $=.310 ; \mathrm{r}$ female $=.410$ ), suggesting a redundancy of information with the father being experienced more negatively when the family environment was less cohesive.

The analysis conducted on CAM and CONFLICT (hypothesis: a conflicted family environment in which the child experienced problems with the mother could contribute to an increased EAT) indicated that these variables were 
significant for the overall sample $(p=.001)$ and for the female sample $(p=.006)$. For both samples only the CONFLICT variable made a significant contribution, outweighing the information provided by CAM. The correlation of CAM with EAT was low $(r=.143$ for the female sample, $r=.036$ for the male sample, $r=.111$ overall). There was a strong correlation between CAM and CONFLICT $(r=.372$ for the sample overall, $r=.521$ for the female sample) suggesting a strong redundancy between these variables that would account for the above finding.

Adding the dimension of family cohesion (CONFLICT + COHESION + CAM; hypothesis: a highly conflicted family environment in which the mother was overly involved and viewed negatively could contribute to an increase in eating disturbances) yielded significance for all three samples ( $p$ overall $=.002 ; \mathrm{p}$ male $=.033 ; \mathrm{p}$ female $=.016)$. COHESION was a significant contributing dimension only for the male sample $(p=.047)$, and CAM provided no significant contributing information for any of the samples. Thus, for the sample overall and for the female sample, CONFLICT was the only significantly contributing variable, outweighing the contributions by COHESION and CAM. As noted earlier, the correlation of CONFLICT with COHESION and CONFLICT with CAM were high for the overall sample and the female sample, accounting for the current findings of this multiple regression. 
In this analysis, a slightly positive correlation of COHESION with the other variables was seen for the female sample (coefficient $=.086$ ), suggesting that women were more sensitive to a less cohesive family rather than an overly involved one. For the male sample, the correlation was in a negative direction (coefficient $=-2.169$ ), suggesting that men were responding negatively more when the family members were overly involved with one another. This gender difference in response to degree of family cohesion is seen more clearly when the correlations of COHESION with EAT directly are examined: for the male sample, $r=-.135$; for the female sample, $r=.173(p<.05)$.

\section{SECONDARY ANALYSIS}

\section{$\underline{\text { Problem }}$}

After completing the primary analysis, I examined the family relationship and eating disorder questionnaires more closely. I became interested in teasing out some of the findings in more detail. For example, why did family conflict supercede many of the other variables in the multiple regression analyses? What was the particular experience of conflict that was important--did it pertain to an issue of family power or control, or the degree of involvement of a particular parent rather than between family members overall? Also, what was it about the 
relationship with the father that it loomed as significantly more important than the relationship with the mother (the correlation of CAF with EAT for the overall sample was $r=.238$; for men, $r=.133$; for women, $r=.259$; the correlation of CAM with EAT: r overall=.1ll; for men, $r=.036$; for women, $r=.143)$ ?

I was also curious about the different psychological facets of an eating disorder. Clinical explorations of eating disordered patients' experiences have suggested that their disturbance and behavior with food means and expresses different phenomena at different times. Themes of control, of attempts to empower oneself when having felt powerless, and of denial vs. expression of one's needs thus figure prominently in varying times and situations. I wanted to explore what particular family constructs might account for some of these different internal experiences. As the clinical literature suggests, these dimensions are quite subtle. I wanted to develop family relationship variables that would be more sensitive and discriminatory towards some of these nuances.

The primary multiple regression analyses suggested that some of the family variables were too broad or nonspecific to be able to determine precisely what was occurring. For example, the CONFLICT variable, comprised of twelve items, was seen to include some questions that pertained to overt conflict, others that referred to a chaotic, leaderless 
environment, and others that involved family emotional expressiveness and acceptance. The CAF/CAM yielded only an overall score of degree of like/dislike in the relationship with the father or mother: upon inspection, certain

questions were determined to be able to yield more specific information.

Subscale Construction and Scoring

Spurred by these concerns and observations, I analyzed the content of each item in the eating disorder and family relationship sections to determine what precise constructs each encompassed. Thus, on the eating disorder scale, "Like my stomach to be empty" was seen to refer to a denial of needs, "Feel extremely guilty after eating" was seen as feeling guilty after meeting one's needs, "Eat the same foods day after day" demonstrated the importance of being in control, and "Feel that others would prefer if I ate more" suggested a dimension of empowering oneself socially, gaining attention and recognition and envy of others through one's eating habits. BY this process, a total of twenty questions were selected and rationally clustered together into six subdimensions according to a logical understanding of their referents.

The subdimensions were named and defined as follows: EATNEEDS (eight items) referred to how people used food as a way to manage their needs. EATCNTRL (four items) 
referred to control people had over themselves as manifest in the control they had over the food they took in. EATPHPOW (four items) involves people empowering themselves physically (i.e., by exercising strenuously to burn off calories). EATSOCPW (five items) encompasses the social dimension of a person feeling empowered in relation to other people (i.e., by resisting the pressure of others who want them to eat). Two subscales were identified to determine anorectic (AN: eight items) and bulimic (BU: four items) tendencies. There was some overlap among the six subdimensions that were defined (see Appendix E for item inclusion).

Three subdimensions were defined on the CAF. CAFINVLV (Nos. 6, 9, 10, and 14) referred to the degree to which the father was perceived as being involved in the child's life, and included questions such as "My father interfered with my activities." CAFHOSTL (Nos. 1, 4, 13, 19, and 20) referred to hostility experienced towards the father, and CAFCNTRL (Nos. 9 and 10) described the feelings of being controlled by the father ("My father put too many limits on me").

Four subdimensions were defined on the SFI (the 36 item section involving family relationships as the person was growing up). SFINEEDS (Nos. 1, 9, 12, 20, 22, and 28) identifies how needs were managed in the family (e.g., "Family members paid attention to each other and listened 
to what was said"). SFICHAOS (Nos. 5, 8, 14 and 16) refers to the degree of chaos present in the family (e.g., "There was confusion in our family because there was no leader"). SFIPOWER (Nos. 16 and 32) looked at the presence of power relationships in the family ("The grownups in this family were strong leaders"), and SFIHOSTL (Nos. 5, 14, 18, 23 and 31) measured hostility in the family ("The grownups in the family competed and fought with each other"). CAFHOSTL and SFIHOSTL were collapsed together into HOSTILE, a dimension indicating overall hostility with a particular valence towards the father.

Other variables defined in this secondary analysis involved specific scores to do with feelings about weight gain, and current weight, in order to examine correlations between these and the overall eating disorder score. CURRWT reported the person's score on question 15 of the Health and Nutrition History, with a score of 1 given to a report of being extremely overweight, and a 5 given for being extremely thin. WTGAIN (question 18: "How much does a two-pound weight gain or loss affect your feelings about yourself") was scored with 1 given to a "not at all" response, and a 5 to a response of "extremely." A final score, EXTREMES, was derived by examining the pattern of responses on the family relationship sections. A person was defined as having extreme responses if they responded with a 1 or a 5 more than $50 \%$ of the time. If the 
responses were all positive or all negative, this

unidirectional response pattern was given a score of 1 . If the person was ambivalent, with both positive and negative responses given, this bidirectional response was given a score of 0 . People who did not respond in an extreme manner were not scored, with a total of 78 people lout of the overall $\mathrm{N}=167$ ) providing extreme answers.

\section{Analysis}

Descriptive statistics were obtained, with mean, range, and standard deviation reported on all variables in Appendix F. Person product moment correlations were computed for all pairs of variables. Table VII presents the correlations for all the variables with the eating disorder score.

\section{TABLE VII}

SECONDARY ANALYSIS: CORRELATIONS OF EAT WITH ALL OTHER VARIABLES

\begin{tabular}{|c|c|c|c|}
\hline$\frac{\text { VARIABLES }}{\text { SEX }}$ & $\frac{\text { OVERALL }}{.295^{\star \star}}$ & MALE & FEMALE \\
\hline CURRWT & -.060 & -.139 & .117 \\
\hline WTGAIN & $.448 * \star \star \star$ & $.529 * * *$ & $.320 * \star$ \\
\hline CAFINVLV & .182 * & $.249 *$ & .148 \\
\hline HOSTILE & $.184^{\star}$ & $.230^{\star}$ & .187 \\
\hline CAFCNTRL & . $179 *$ & .203 & .140 \\
\hline SFINEEDS & .151 & .036 & .177 \\
\hline SFICHAOS & $.171 *$ & .120 & $.234 *$ \\
\hline SFIPOWER & .044 & -.080 & .069 \\
\hline EATNEEDS & $.762 \star \star \star$ & $.610 * \star \star *$ & $.813 * \star \star$ \\
\hline EATCNTRL & $.568 * * *$ & $.520 * * *$ & $.646 * * \star$ \\
\hline EATPHPOW & $.646 \star \star \star \star$ & $.622 * \star \star \star$ & $.720 * \star \star *$ \\
\hline EATSOCPW & $.466 \star \star \star \star$ & $.318 * \star$ & $.545 * \star \star$ \\
\hline AN & $.610 * \star \star$ & $.571 * \star \star$ & $.648 * \star \star$ \\
\hline$B U$ & $.546 \star \star \star$ & $.540 \star \star \star *$ & $.528 * * *$ \\
\hline EXTREMES & -.127 & -.181 & -.113 \\
\hline
\end{tabular}


A complete correlation matrix for the overall sample and for men and women separately appears in Appendix G.

Secondary Multiple Regression Analysis

A multiple regression analysis was performed to examine the effects of several of the family variables concurrently in relationship to various eating disorder variables. Summary results of these analyses are given in Tables VIII-XI, along with a statement of each hypothesis. Table XII presents the correlations for each pair of independent variables used in the multiple regression, to examine any relationship that may exist between them. Table XIII presents the significance levels for the individual variables used in each multiple regression analysis that examined the effects of more than one variable concurrently.

Table VIII includes the hypotheses related to questions of power, control, and management of needs, both in the family and as manifest in the person's eating disturbance. SFINEEDS was correlated significantly with EATNEEDS in both the Pearson pairwise correlation and the multiple regression correlation for the sample overall ( $r=.183$, $\mathrm{p}=.018)$ and for the female sample $(\mathrm{r}=.241, \mathrm{p}=.022)$, in a test of the hypothesis that a family environment in which needs were denied could contribute to an increase in the person's denial of their own needs as indicated through 
TABLE VIII

MULTIPLE REGRESSION ANALYSES: POWER, CONTROL, AND NEEDS IN THE FAMILY AND IN THE EATING DISTURBANCE

$\underline{\text { SAMPLE }} \underline{\mathrm{N}} \underline{\mathrm{F}-\mathrm{RATIO}} \underline{\mathrm{P}} \underline{\mathrm{R}} \underline{\underline{\text { MQUARED }}}$

1) EATNEEDS = SFINEEDS

Hypothesis: A family environment in which needs were denied could be associated with an increase in the person's denial of their own needs.

$\begin{array}{lrrrrr}\text { Overall } & 167 & 5.722 & 0.018 & .183 & .034 \\ \text { Male } & 77 & 0.018 & 0.893 & .016 & .000 \\ \text { Female } & 90 & 5.411 & 0.022 & .241 & .058\end{array}$

2) EATCNTRL = SFICHAOS

Hypothesis: In a chaotic family environment, a person might be attempting to increasingly control their environment through controlling their food intake.

$\begin{array}{lccccc}\text { Overall } & 167 & 0.955 & 0.330 & .076 & .006 \\ \text { Male } & 77 & 0.285 & 0.595 & .061 & .004 \\ \text { Female } & 90 & 3.144 & 0.080 & .186 & .034\end{array}$

3) EATPHPOW = SFIPOWER + CAFCNTRL

Hypothesis: A family environment in which the father was a very powerful figure could be associated with the child feeling powerless and trying to empower $\mathrm{him} / \mathrm{h}$ erself through control of food and exercise.
Overall
151
0.742
0.478
.010
Male
66
0.789
0.459
.024
Female
$85 \quad 1.308$
0.276
.031

4) EATSOCPW $=$ SFIPOWER + CAFCNTRL

Hypothesis: A family environment in which the father was a very power figure could be associated with the child feeling powerless and trying to empower her/himself in a social way through her/his use of food.
Overall
151
3.376
0.037
.044
Male
$\begin{array}{ll}66 & 0.094\end{array}$
0.911
.003
Female
$85 \quad 3.661$
0.030
.082

their avoidance of food. Examining the correlation of SFICHAOS with EATCNTRL was nonsignificant for all samples, 
disconfirming the hypothesis that in a chaotic family environment, a person might be attempting to increasingly control their internal and external environment through controlling their intake of food.

\section{TABLE IX}

MULTIPLE REGRESSION ANALYSES: THE RELATION BETWEEN THE FATHER'S INVOLVEMENT AND EATING DISTURBANCE

$\underline{\text { SAMPLE }} \underline{\mathrm{N}} \underline{\text { F-RATIO }} \underline{\mathrm{P}} \quad \underline{\mathrm{R}} \underline{\text { MULTIPLE }}$

1) $\mathrm{EAT}=$ CAFINVLV

Hypothesis: An uninvolved father could contribute to an increased eating disturbance, as the person tries to gain his recognition and involvement.

$\begin{array}{lrrrrr}\text { Overall } & 161 & 5.420 & 0.021 & .182 & .033 \\ \text { Male } & 72 & 4.629 & 0.035 & .249 & .062 \\ \text { Female } & 89 & 1.959 & 0.165 & .148 & .022\end{array}$

2) EATSOCPW = CAFINVLV

Hypothesis: An overly involved father could be associated with the child feeling powerless and attempting to empower him/herself interpersonally through manipulations with food.

$\begin{array}{lrllll}\text { Overall } & 161 & 6.336 & 0.013 & .196 & .038 \\ \text { Male } & 72 & 0.306 & 0.582 & .066 & .004 \\ \text { Female } & 89 & 6.131 & 0.015 & .257 & .066\end{array}$

3) EAT = CAFINVLV + HOSTILE

Hypothesis: An environment with a highly involved father towards whom the person felt hostile could be associated with an increased eating disturbance.

$\begin{array}{lrrrr}\text { Overall } & 161 & 4.510 & 0.012 & .054 \\ \text { Male } & 72 & 3.305 & 0.043 & .087 \\ \text { Female } & 89 & 2.067 & 0.133 & .046\end{array}$


MULTIPLE REGRESSION ANALYSES: RELATION BETWEEN CURRENT WEIGHT, FEELINGS ABOUT A SMALL CHANGE IN WEIGHT,

AND THE OVERALL EATING DISORDER SCORE

$\underline{\text { SAMPLE }} \underline{N} \underline{\text { F-RATIO }} \underline{P} \quad \underline{R} \underline{\text { SQUARED }}$

1) $\mathrm{EAT}=$ WTGAIN

Hypothesis: An eating disordered person would be more likely to be sensitive to a small change in weight.
Overall
167
41.361
$0.000 \quad .448$
.200
Male
$77 \quad 29.125$
$0.000 \quad .529$
.280
Female
$90 \quad 10.063$
$0.002 \quad .320$
.1032

2) EAT $=$ CURRWT

Hypothesis: Eating disordered people are likely to be normal- or under-weight.
Overall
$\begin{array}{ll}167 & 0.587\end{array}$
$0.445-.060$
.004
Male
$77 \quad 1.484$
$0.227-.139$
.019
Female
$90 \quad 1.219$
$0.273 \quad .320$
.014

\section{3) EAT = WTGAIN + CURRWT}

Hypothesis: A thin or normal weight person affected by weight change could show an increased eating disturbance.

Overall

Male

Female
167

77

90
20.727

16.146

5.514
0.000

0.000

0.006
.202

.304

.112

\section{TABLE XI}

MULTIPLE REGRESSION ANALYSES: THE RELATION BETWEEN A PERSON'S PATTERN OF RESPONSES AND THEIR ANORECTIC OR BULIMIC INCLINATIONS

$\underline{\text { SAMPLE }} \underline{\mathrm{N} \text { F-RATIO }} \underline{\mathrm{P}} \underline{\mathrm{R}} \underline{\text { MULTIPLE }}$

1) EXTREMES = BU

Hypothesis: A person with ambivalent extreme responses would be more likely to show bulimic tendencies.

$\begin{array}{llllll}\text { Overall } & 78 & 0.608 & 0.438 & -.089 & .008 \\ \text { Male } & 32 & 5.357 & 0.028 & -.389 & .152 \\ \text { Female } & 46 & 0.172 & 0.680 & -.062 & .004\end{array}$

2) EXTREMES $=\mathrm{AN}$

Hypothesis: A high extreme unidirectional perspective could be seen in a person with anorectic tendencies. Overall

Male

78

32

0.135

$0.714-.042$

0.704

$0.408 \quad .151$

.002

Female

$46 \quad 0.439$

$0.511-.099$

.023

.010 
TABLE XII

SECONDARY ANALYSIS: CORRELATIONS FOR PAIRS OF INDEPENDENT VARIABLES USED IN THE MULTIPLE REGRESSION

VARIABLES

SFIPOWER + CAFCNTRL

CAFINVLV + HOSTILE

WTGAIN + CURRWT \begin{tabular}{c} 
OVERALL \\
\hline .039 \\
.593 \\
-.051
\end{tabular} $\frac{\text { MALE }}{.058}$

.471

.030 $\frac{\text { FEMALE }}{.013}$

.652

.055

\section{TABLE XIII}

SECONDARY ANALYSIS: SIGNIFICANCE LEVELS FOR

INDIVIDUAL VARIABLES USED IN THE MULTIPLE REGRESSION ANALYSES THAT UTILIZED MORE THAN ONE VARIABLE

1) EATPHPOW $=$ SFIPOWER + CAFCNTRL

OVERALL

MALE

FEMALE

VARIABLE

SFIPOWER CAFCNTRL SFIPOWER CAFCNTRL SFIPOWER CAFCNTRL $\frac{P(2 \text { tail })}{.413}$

2) EATSOCPW $=$ SFIPOWER + CAFCNTRL

VARIABLE

$$
\text { OVERALL }
$$

MALE

FEMALE

SFIPOWER CAFCNTRL SFIPOWER CAFCNTRL SFIPOWER CAFCNTRL $\frac{P(2 \operatorname{tail})}{.575}$

$$
.013 \quad .969
$$

.670

.509 .011

3) $\mathrm{EAT}=$ CAFINVLV + HOSTILE

VARIABLE

$$
\text { OVERALL }
$$

MALE

FEMALE

CAFINVLV HOSTILE CAFINVLV hOSTILE CAFINVLV HOSTILE $\frac{P(2 \operatorname{tail})}{.437}$ .063 .213 .170 .910 .146

4) EAT $=$ WTGAIN + CURRWT

VARIABLE

$$
\text { OVERALL }
$$

MALE

FEMALE

CURRWT

WTGAIN

CURRWT

WTGAIN

CURRWT

$\frac{P(2 \text { tail })}{.000}$

.601

.000 
Two multiple regression analyses were conducted testing the notion that a family environment in which the father was a very powerful figure could contribute to the child feeling powerless and trying to empower him/herself through his/her relationship with food. In the first analysis, the dimensions of SFIPOWER and CAFCNTRL were examined concurrently for their relationship with EATPHPOW, looking at the way in which a person may be empowering her/himself physically through control of food and exercise. The correlations of SFIPOWER and CAFCNTRL were extremely low ( $r=.039$ overall sample; $r=.058$ male sample; $r=.013$ female sample) suggesting that these variables are measuring different constructs. The correlations of SFIPOWER with EATPHPOW were very low (overall $r=.056$; male $r=-.064$; female $r=.174$ ), and of CAFCNTRL with EATPHPOW were also quite low (overall $r=.119$; male $r=-.104$; female $r=.135$ ). In the second analysis looking at the question of paternal power, SFIPOWER and CAFCNTRL were examined for their relationship with EATSOCPW. In this context, the person was seen to be attempting to empower her/himself in a social way, i.e., in their interpersonal relationships (people would see them as too thin, envy their willpower, pay attention to them for their denial of food, etc.). The results were significant for the sample overall $(p=.037)$ and for the female sample $(p=.03)$ with CAFCNTRL providing the only significant contribution, outweighing the input 
from SFIPOWER. These findings are confirmed by the correlations of SFIPOWER with EATSOCPW (nonsignificant for all samples) and of CAFCNTRL with EATSOCPW ( $r$ overall $=.202, \mathrm{p}<.02 ; \mathrm{r}$ female $=.283, \mathrm{p}<.01 ; \mathrm{r}$ male $=.036$, nonsignificant).

Table IX includes the hypotheses related to the degree of involvement of the father in the child's life and the impact that may have had on the child being increasingly disturbed in their relationship to food. The correlation of CAFINVLV with EAT (hypothesis: an uninvolved father could contribute to an increased eating disturbance, as the person tries to gain his recognition and involvement) was significant for the overall sample $(r=.182, p=.021)$ and for the male sample $(\mathrm{r}=.249, \mathrm{p}=.035)$. However, the correlation was positive, rather than negative, indicating that the EAT score increased as the level of father's involvement increased. Examining the correlation of CAFINVLV with EATSOCPW (hypothesis: when the father was overly involved, this could contribute to the child feeling powerless and attempting to empower themselves interpersonally through their manipulations with food) yielded a significant correlation for the sample overall $(r=.196, p=.013)$ and for the female sample $(r=.257, p=.015)$. Thus, the male and female samples were both affected by the degree of the father's involvement, but were affected in different subdimensions (EAT overall vs. EATSOCPW). 
A multiple regression analysis was conducted combining the variables CAFINVLV + HOSTILE and examining the relationship with EAT (hypothesis: being raised in an environment with a highly involved father towards whom the person felt hostile could contribute to an increased eating disturbance). The results were significant for the sample overall $(p=.012)$ and for the male sample $(p=.043)$. In the overall sample, the only nearly significant contributing variable was the degree of hostility present $(p=.063)$, which outweighed the degree of the father's involvement. For the male sample, neither family variable provided a significant contribution of its own, suggesting that these variables are redundant enough that neither of the unique effects was large enough to be significant. This is supported by the correlation of CAFINVLV with HOSTILE: $r$ overall $=.593, r$ male $=.471, r$ female $=.652$.

Table $X$ presents the hypotheses regarding relationships between current weight and the feelings about a two-pound weight gain or loss with the overall eating disorder score. The feelings about a change in weight were found to be highly significantly correlated with the EAT score for all the samples: $r$ overall $=.448, p=.000 x ; r$ male $=.529, p$ $=.000 x ;$ female $=.320, p=.002$. A person's current weight was not significantly correlated with their eating disorder score for any sample, disconfirming the hypothesis that eating disordered people might be more likely to be normal 
weight or too thin. Combining these variables together (WTGAIN + CURRWT, hypothesis: a thin or normal weight person highly affected by a change in weight would demonstrate an increased eating disturbance), was significant for all samples; $p$ overall $=.000 x, p$ male $=.000 \mathrm{x}, \mathrm{p}$ female $=.006$. The dimension of the person's current weight added no significant information for any of the samples.

Table XI includes the hypotheses examining the relationship between a person's pattern of responses and their anorectic or bulimic inclinations. In the correlation of the bulimic subscale (BU) with the person's pattern of extreme responses, the hypothesis tested was that a person with ambivalent extreme responses (a low score) would be more likely to show bulimic tendencies (high score), as ambivalence is also seen in the oscillation between gorging and vomiting food. Although nonsignificant for the overall and female samples, for the male sample ( $N=32$ respondents in this category), the results show that $r=-.389, p=.028$. The negative correlation supports the hypothesis as well. Examining the correlation of the extreme responses with the anorectic subscale (AN) (hypothesis: high extreme unidirectional perspective would be seen with anorectic tendencies) was nonsignificant for all samples. 


\section{CHAPTER V}

\section{DISCUSSION}

\section{GENERAL CONSIDERATIONS}

A sample of college students was studied as a group and divided by gender: first, to scale the prevalence of eating disorders, and second, to examine the possible relation of family variables to the overall degree of eating disorder and to rationally-created dimensions of eating disordered experience.

A college sample was chosen for study to pursue further reports of the high incidence of eating disorders in college populations. Pyle, Mitchell, Eckert, Halvorson, Neuman, \& Goff (1983) summarize a number of studies suggesting a high prevalence of bulimia in young adults, and other studies have broadened this prevalence to include anorexia as well (e.g., Boskind-Lodahl \& White, 1978). College samples are also more readily accessible for study: few studies have been reported so far on the prevalence of eating disorders in the community at large (Pyle \& Mitchell, 1986).

A nonclinical sample was selected because the bulimic and anorectic symptomatology has been seen to a significant degree in people who have not sought treatment for their 
disorder (Halmi, Falk, \& Schwartz, 1981). Due to the shame often experienced with an eating disorder, this may be an underreported and overlooked problem. Button and Whitehouse (1981) suggest that many people are eating disturbed without carrying a diagnosis or seeking treatment. Additionally, by using a nonclinical broad college population, the "nondisturbed" respondents might provide the "normal control" group against which the more disordered subjects could be compared.

A college sample is limited in that it is certainly not representative of the general population. The sample used in his study was gathered at a large urban working class university. As a broad age range and family background was seen, this offset some of the bias inherent in a college sample. However, since the sample was not stratified nor was the selection process random, similarities to the general population cannot be drawn. Other college samples studied have yielded varying results regarding prevalence, partly reflecting a difference in locale (i.e., Eastern metropolitan sample versus a more rural Midwestern sample) and different student groups used (drawn randomly at registration or from specific classes) (Halmi, et al.. 1981, vs. Pyle, et al., 1983). Conclusions about prevalence of eating disorders in college students must be qualified as well. 
The measurement tool used was selected for its ease of usefulness and applicability for a large sample, and for the opportunity to use systematic data-gathering and scoring procedures in relation to the family relationship and eating disorder scales. The Likert scoring technique allowed for a tentative demarcation of "normal controls" against which the higher scoring eating disturbed subjects might be compared. However, these scales were also found to be limited in the conclusions that could be drawn from them. These particular measurement tools have not been used in other studies, Iimiting the comparison with other research that has been done in this area.

Correlational analyses are not able to address questions of causality, although they can illuminate areas to be pursued through direct observation, interviews with all family members, etc., to explore potential causality further. The multiple regression analysis adopted for this study provides information regarding general weighting of variables that may be associated with a particular variable such as an eating disorder score but does not allow for a clearer discovery of family variables that might distinguish between three criterion groups such as "eating disordered," "intermediate," and "normal." To be able to study further that distinction, it would be necessary to have three comparably sized groups on which a discriminant analysis would be conducted. 


\section{OVERALL OBSERVATIONS}

While it is not possible to diagnose people as eating disordered based solely on the responses to a self-report questionnaire, 168 of the women and 48 of the men scored above the cut-off range of what is defined as eating disordered on the EAT Scale (Garner \& Garfinkel, 1979). This is consistent with the previous prevalence statistics for this population (Halmi, et. a., 1981; Pyle \& Mitchell, 1986).

Additionally, a large subgroup was seen in both the male and female samples who demonstrated an intermediate level of eating disorder but not the full syndrome. After dividing the samples into eating disordered, intermediate, and normal subjects, the subgroups were of such disparate sizes that it was not possible to analyze with reliability differences that might exist between these groups regarding family constellations or interaction patterns. Instead, a study was made of relations between an increased eating disorder score and a variety of family variables. No scales measuring the occurrence of anorexia or bulimia were used, so the incidence of these specific disorders could not be studied in this sample.

of particular interest in the findings was the large size of the intermediate subgroups of eating disturbed 
respondents, particularly among the men. Button and Whitehouse (1981) examined subclinical eating disorders focusing on women who scored high on the EAT but who were not diagnosed as anorectic. They proposed that

at least 58 of young post-pubertal females experience psychological problems associated with weight; a larger proportion may have resulted if a lower EAT cut-off score had been used. Cases of anorexia nervosa . . . may be regarded as . . . the tip of the iceberg with respect to excessive weight concern among young females (p. 514-515).

The use of a lower cut-off score in this study supports this suggestion. The lower cut-off score also allowed for the determination that over half of the men had some degree of concern about weight and body image, a much higher percentage than has ever been reported in the literature. Thus, although the incidence of fully diagnosable eating disorders continues to be much higher in women than men, men are seen to be much more preoccupied with food and weight than the literature suggests. Whether this is a newer trend reflecting increased sociocultural pressures around body image, or whether this is further evidence that women are more likely to seek treatment for psychological concerns than men--with the consequence that the concerns of men receive less attention--is not currently known. Questions regarding correlations of socio-economic status with eating disorder could not be addressed 
adequately in this study. Twenty-five percent of the respondents did not answer questions regarding parents' occupation or income level, and some other respondents answered in ways that seemed inconsistent (e.g., a business manager of a large concern reported by his child to earn $\$ 10,000$ a year), raising the question of how accurate subjects' information was regarding parental socio-economic status.

Classification into a particular occupational category was also problematic. People mentioned some difficulty in knowing how to classify their parents. The classification used was based on the Department of Labor Classification of Occupations, which is based on a demographic approach with occupations clustered according to income.

A particular area of interest in this study was the impact of maternal employment upon the development of eating disorders in children. Two hypotheses were considered: 1) would the absence of the mother from the home (as she worked in paid employment) be associated with an increase in eating disturbance because the child tried to cope with the conflict that he or she experienced about his or her emotional needs through a preoccupation with food, either trying to control and deny emotional needs through restrictions or purging of food, or by compensating for emotional deprivation through overeating?

2) Would the 
identification of a daughter with a mother, who was seen to possess some authority through working in paid employment, assist the daughter in achieving a sense of her own power so that she was not compelled to try to empower herself through her manipulations with food?

The socio-economic questions seemed to be so confusing or difficult to answer that these hypotheses were not tested. Certain implications of the data will be presented, but definitive conclusions cannot be drawn. The questionnaire also did not include the direct question of whether the mother worked outside the home or not, a question necessary to examine the contribution of out-of-home employment to the development of eating disturbances. However, responses did assess a perceived hierarchy of maternal employment allowing some examination of the question of whether a mother rated higher on the occupational scale might be perceived as more powerful due to her higher status job, permitting associations of work status and other variables.

There is a also a structural way of viewing employment, in which categories are based on degree of autonomy, intensity of supervision and the degree of control that a person has over their own work as well as over that of others. Some of the clumpings of occupation used in this study didn't fit together from this structural perspective: 
this may explain some of the difficulty that people had in classifying their parents.

\section{FEMALE SAMPLE}

Many of the family dimensions of the questionnaire were significantly related to eating disorder scores for the women but not for the men. This may be an artifact of the increased incidence of eating disturbances and eating disorders in the female sample. The larger numbers of cases may allow the finding of significant relations in the sample of women. This difference may also mean that men and women respond to different family dimensions, and may also demonstrate this in different forms, i.e., with differential experiences with food being important for each gender.

of the four hypotheses concerning mother's occupation, presence of leadership in the family, and a measure of emotional expressivity, all were significant for the female sample and not for the male sample. The mother's occupational status was significantly correlated with the degree of eating disorder alone, and continued to provide significant information when combined with the variable treated as emotional expressiveness. The dimension of maternal occupation also superceded the contribution of information from the emotional dimension. Bearing in mind 
the earlier caveat about this occupational dimension, these findings suggest that the mother's higher-status employment was a source of stress for her daughter and that the daughter may have responded to this stress of the more absent and busy mother by manifesting a disturbance with food and weight. This would disconfirm the hypothesis that a daughter might find comfortable identification with her able, employed mother and thus show more comfort with herself.

However, as my continuing discussion of the results indicates, mother's occupation was a relatively insignificant contributing factor in eating disorders among the female sample. When mother's occupation was examined in combination with the dimension of leadership present in the family (Table III), a chaotic (i.e., lack of leadership) family environment was the only significant factor, and the mother's work status no longer made a significant contribution. The lack of leadership also outweighed the dimension of emotional expressiveness in the family. The high correlation of mother's occupation with leadership indicated that the higher status of maternal employment was experienced as more chaotic: perhaps one dimension of the chaos arose from the mother's absence. The eating disorder could have emerged in response to family chaos rather than being directly associated with maternal absence per se, with the daughter trying to 
provide more order to her experiences through her control over food and her body. On the other hand, the families could have been more chaotic in response to dealing with the daughter's eating disorder. The variance of the sample accounted for by any of these findings was less than $13 \%$, indicating that although something is occurring between the chaos in the family and the presence of an eating-disturbed daughter, it is not accounting for much of what is occurring for eating disordered women.

Examining the hypotheses concerning family conflict, family cohesion, presence of leadership, and the child's attitudes towards each parent, certain gender differences emerged, although they were less clearly dichotomized than was true of the findings previously mentioned. The variable of family conflict was significantly correlated with an increased eating disturbance for both men and women; the relationship was especially strong for women. When combining the variable of conflict with the others in various combinations, it remained the only variable contributing significant information for the female sample, overriding the relationship of the eating disordered score with leadership, family cohesion, or the daughter's attitude towards her father. These variables provide stronger relationships when examined singly in relationship to the eating disorder score. This may reflect a 
heightened sensitivity of daughters to family conflict. However, family conflict was also found to be highly correlated with family cohesion, leadership, and the child's attitude towards either parent. This suggests that family conflict may be expressed in myriad ways: as lack of family cohesion or lack of leadership or with problems with a parent. Hence these variables may all be measuring a single comprehensive underlying variable.

The family conflict variable was comprised of many more scale items than were the cohesion or leadership variables. Perhaps this may be a more reliable variable that could outweigh the others by virtue of this increased item inclusion. This question of subscale relative reliabilities needs to be pursued further.

Gender differences were found in the dimension of family cohesion. Although this variable may have had less weight than family conflict for the female sample, the positive direction of the correlation of cohesion with the eating disorder score indicates that women may be more sensitive to a family where cohesion is lacking. As will be discussed below, men were sensitive both to family conflict and cohesion, and were more sensitive to an excessively cohesive and involved, rather than noncohesive, family.

A surprising finding was the lack of significant correlation between the attitude towards the mother and 
increased eating disturbances for either the women or the men. The psychoanalytic perspective traditionally places great emphasis on the relationship with the mother contributing to either relative health or psychological disorders in children. The current study suggests that the relationship with father is more related to the presence of eating disorders than is the relation with mother. It suggests that family variables such as conflict and cohesion have even more weight than the relationship to either parent. This may indicate that an approach which examines the family as a system is more pertinent than examining the relationship with either parent individually. Perhaps identification with and responses to problems with either the mother or the father are less important contributors to eating disorders than are questions of how closely the family members are involved with one another or how much conflict exists in the family. These findings regarding the relative significance of the relationship with each parent may also reflect shortcomings in the particular family questionnaires that were used. A number of the subjects in this study scored their feelings towards their mother in a quite extreme positive fashion. Clinicians often view such extreme favorable responses as being suspect, as it is unlikely that a parent could have been so uncritically accepted by the subject. Therefore, in self-report questionnaires, it 
may be easier for subjects to remember and report on difficulties with the father than the mother.

Another shortcoming of the family instruments is that all the subdimensions (family cohesion, conflict, etc.) were not specific to individual parents, but reported as part of a general family environment. Most of the questions on the CAF/CAM were not specific to a particular emotional dimension of that relationship e.g., "I disliked my father" gives no indication of why a person may feel that way), so attempts at defining subscales on this instrument were limited by the number of questions that could provide illuminating information. This lack of specificity does not allow for a closer examination of nuances in the relationship with either parent, and therefore omits from view input from other family members that may positively offset difficulties with one family member.

In reviewing the secondary analysis, in which different family and eating disorder subdimensions were defined and examined to amplify the above findings, gender differences again appeared. When the dimensions of management of needs and experiences of power were examined both within the family and as manifest in the person's eating disturbance, the experience of eating disturbances among women seemed to be in part a method both for managing needs and for empowering themselves. Although these findings accounted 
but for a small percentage of the variance, they were highly significant for the female sample. The dimension of empowering herself socially, i.e., through the way in which she was perceived by others for being able to be so much in control, etc., was also found to be more important than the sense of physical power acquired by controlling her body through exercise and reduced caloric intake.

These findings support psychoanalytic feminist descriptions (Chodorow, 1978) that women in our culture today face many more ambiguities and conflicts about their emotional needs and their ability to be seen as powerful. Even as women are increasingly entering the paid work force, often in higher management positions with a diversity of role options and opportunities, a stereotype of femininity persists (Orbach, 1986). Men more readily achieve and are respected and reinforced for being autonomous and independent than are women (Gilligan, 1982). There has been a general historical trend since WWII towards greater autonomy and possibilities in this society for women. This creates new conflicts between old inhibitions and dependencies and new possibilities and expectations for autonomy.

College, by definition, is a transitional period, with students being educated towards new possibilities and responsibilities in society. Women today are expected both to work and to build a family, creating significant 
pressure. It has also been noted that women tend to provide emotional labor through service to others (Hochschild, 1984); thus, their independence is even seen to contain an affiliative component. Therefore, a woman's needs continue to be denied even as she attends to those of others, and her sense of self-definition is primarily attained through her affiliation with another and her deference to others. Women are thus aware of the intensity of their needs and desires, but are unable to express and respect their emotional lives and to develop a sense of themselves as autonomous people.

Eating disorders, particularly in a college sample, may in part be an expression of dependence/independence conflicts among contemporary women. In the current study, women were found to be particularly sensitive to a chaotic or conflictual family environment, and to families in which the members were not closely involved with one another. This supports the above noted inclination of a woman to attend to the needs of others and to define herself through her affiliations. In the kinds of families just described, a woman might feel a sense of loss, failure, and discomfort, and use food as one way of managing these feelings. Denying her own needs through not eating, through purging after eating, or through the preoccupation with food, can be seen not only as putting her own needs second to those of others, but might also be a form of 
self-punishment for having failed in her attempt at creating a smooth, warm, nurturing family environment. At the same time, the woman may be quite frustrated by her lack of power in this kind of family, and may be trying to empower herself even as she is making herself smaller and less intrusive through eating or retaining less food.

\section{MALE SAMPLE}

Upon examining the findings on the primary and secondary analyses for the male sasmple, different dimensions from those in the female sample emerged as significant. As indicated earlier (Table IV), a conflictual family environment was also an important parameter for men, both when examined singly in relationship to the degree of eating disturbance, and also when combined with other family variables. For the male sample, family cohesion remained a significant contributing variable even when combined with other family variables, and the negative correlation of cohesion with the eating disorder score indicates that men responded to an excessively cohesive, overly-involved family. Neither the attitude towards the mother or the father emerged as significant for men, nor did the mother's occupational status, presence of leadership in the family, or degree of emotional expressiveness present. 
A finding that was significant for the male sample and not for the female sample was the relationship between the degree of the father's involvement in the family and the degree of overall eating disturbance (Table IX). Although this finding did not account for a large percentage of the variance, the positive correlation between these variables indicates that the more the father was involved in the family, the greater the eating disturbance for the son. The correlation between the degree of the father's involvement and the degree of hostility perceived in the family was quite high, supporting the above possibility. Hence the father may have been perceived as a controlling or prohibiting man whom the son was resisting.

of note was that the dimension of trying to empower themselves through food was not a significant dimension for the men as it was for the women. The eating disturbance also did not appear to be a means for men to manage their needs: neither the correlation of management of needs in the family with the overall eating disorder score nor with the denial of food was significant.

The experience of men thus appears to be quite different from that of women. Men are sensitive to family conflict and also to an environment in which family members are overly involved with one another. Although not particularly sensitive to nuances that were measured in relationship to the mother, men may be engaged in efforts 
to separate themselves from and resist an overly involved, prohibiting father. This may be consistent with the psychoanalytic feminist theses developed by Chodorow (1978) and Gilligan (1982) that whereas women's primary developmental task involves affiliation with others, that of men involves separation from others, with less attention paid to emotional nuances and needs. An extension of this sense of separateness and autonomy for men is that power is an accepted and supported dimension of a man's experience in precisely the way that it is not for women.

The findings in the current study support these aspects of men's experiences, as men are seen to be particularly striving for separateness from an overly cohesive and involved family, but are not seen as trying to empower themselves or deny their needs through their eating disturbance. As mentioned for the findings about women, these findings, although significant, only account for a small percentage of the variance. Therefore, caution needs to be taken in interpreting these findings. In addition, the subdimensions developed for the secondary analysis need reliability and validity data to be gathered in order that the current findings can be pursued further.

Two final areas yielded gender differences. While the relationship between a subject's feelings about a small change in weight and their degree of eating disorder was 
significant for both men and women, the correlation was even stronger for men than for women, indicating that men are much more preoccupied with body image than has been reported. At the same time, the percentage of men who are diagnosed as eating disordered is much smaller than women. Perhaps when men are more troubled in this area, it is manifested as an eating disorder, whereas for women, a certain degree of preoccupation with body image and weight is normative.

Men who responded in an ambivalent extreme manner to questions regarding their families were more likely to show bulimic tendencies; this was not the case for women. Although this finding was derived from a small subset of the male sample, it too suggests, as did the large percentage of intermediate eating-disturbed men, that men are more preoccupied with food and body image than has been apparent. This is a trend that would be important to examine further, to ascertain if indeed men are more eating-disturbed than has been reported, and to examine what factors relate to this phenomenon, if it exists.

\section{CONCLUSION}

The current findings complement the existing extensive Iiterature on family issues related to the presence of eating disorders. In teasing out certain dimensions that have not been previously studied, such as the degree of the 
father's involvement with his child or the lack of significance of the attitude towards the mother, this study suggests that these areas are worthy of further pursuit. This study also offers evidence that overall family dynamics may be of more significance in the etiology of an eating disorder than is the relationship with either parent individually. As many of the findings accounted for only a small percentage of the variance within the sample, it will be important to study other samples in a similar manner to pursue these suggestions further. 
CHAPTER VI

\section{SUMMARY}

The present study raised more questions that it was able to answer. Although this study was an attempt at utilizing a more rigorous methodology than has been used in many studies, problems were seen with the sections of the questionnaire used here as well. The reliability and validity of self-report data is always of concern, as people may underreport their experiences to keep their disorder a secret, or they may overreport information in an effort to please researchers. It is also not possible to clarify the particular meaning for a subject in response to a question or series of questions, which can be problematic when it is determined (as was the case here) that many questions are open to interpretation. Combining the use of a self-report questionnaire with interviews of both the subject and family members could clarify biased or erroneous reports, and lead to further understanding of a subject's experiences.

Due to the correlational nature of the analyses, possible causal family variables could not be defined, and possible preventive measures could not begin to be 
offered. Upon closer inspection, the family subscales that had been defined were seen to lend themselves to only limited interpretation. New subscales were derived in a secondary analysis which provided important insights into the experiences of the subjects both in their relationships with family members and in the nuances of their eating disturbances. The secondary analysis can be seen to provide a means of empirically testing some of the clinical findings that are reported in the psychoanalytic case material, an exciting development that could assist psychoanalytic researchers in defending their claims. These subdimensions were developed by a rational clustering of items that seemed to go together. It is therefore crucial to examine the reliability and validity of these dimensions to further test the clinical suggestions that are ventured here regarding what subjects are trying to express with their eating disturbances, and also to what family factors they may be responding.

A large intermediate eating disorder subgroup was found, both in men and women, supporting suggestions regarding the degree of general problems that people experience in our culture with food and body image. However, it was not possible to identify specific family factors that might contribute to this level of disturbance that is presumed to be less severe than a fully diagnosed 
eating disorder. Due to the large size of this subgroup, it would be an important area to pursue further, to understand what is occurring with this subclinical population.

The findings regarding the association of increased eating disturbances with maternal absence due to her employment and with the degree of the father's involvement need to be viewed with caution. It is certainly not this author's intention to imply that mothers need to remain in the home or that fathers need to be less involved with their sons. One factor cannot be said to be the crucial one in the development of any psychological problem. It is necessary to look at the overall base of support within a family, at extrafamilial social factors, and at the quality of particular dimensions that are defined as important. In this study, it is not known why the mother's absence and father's degree of involvement were significant. To clarify this, the use of supplementary questions or of interviews with the subjects would be necessary.

An area that was of particular interest to the author was that of perceived maternal and paternal power, and their relationship to the development of an eating disorder. Currently no family questionnaires are known that measure this dimension, so it was not studied. This does appear to be an important area to examine further, 
together with the finding that this was a significant dimension of eating disorders for women but not for men. This will entail development of a new questionnaire, with reliability and validity to be determined: this could clearly be an area for future research. 
REFERENCES

American Psychiatric Association. (1987). Diagnostic and Statistical Manual of Mental Disorders. Washington, D.C.

Beavers, W. R., Hampson, R. B., \& Hulgus, Y. F. (1985). "The Beavers systems approach to family assessment." Family Process, 24, 398-405.

Bemis, K. (1978). "Current approaches to the etiology and treatment of anorexia nervosa." Psychological Bulletin, 85, 593-617.

Benjamin, L. S. (1974). "Structural analysis of social behavior." Psychological Review, 81, 392-425.

Beumont, P. J. V., Beardwood, C. J., \& Russell, G. F. M. (1972). "The occurrence of the syndrome of anorexia nervosa in male subjects." Psychological Medicine, 2, 216-231.

Boskind-Lodahl, M. \& White, W. C. (1978). "The definition and treatment of bulimarexia in college women: A pilot study." Journal of the American College Health Association, 27, 84-97.

Bruch, H. (1973). Eating Disorders: Obesity, anorexia nervosa and the person within. New York, NY: Basic Books.

Button, E. J. \& Whitehouse, A. (1981). "Subclinical anorexia nervosa." Psychological Medicine, ll, 509-516.

Chadorow, N. (1978). The reproduction of mothering. Berkeley, CA: University of California Press.

Chediak, C. (1977). "The so-called anorexia nervosa: Diagnostic and treatment considerations." Bulletin of the Menninger Clinic, 41, 453-474.

Chernin, K. (1985). The Hungry Self. New York, NY: Times Books. 
Crisp, A. H. (1983). "Anorexia nervosa: Getting the 'heat out of the system." Psychiatric Annals, 13, (12), 936-952.

Crisp, A. H. \& Burns, T. (1983). "The clinical presentation of anorexia nervosa in males." International Journal of Eating Disorders, 2, (4), 5-10.

Crisp, A. H., Hsu, L. K. G., Harding, B. \& Hartshorn, J. (1980). "Clinical features of anorexia nervosa." Journal of Psychosomatic Research, 24, 179-191.

Crisp, A. H., Palmer, R. I., \& Kalucy, R. S. (1976). "How common is anorexia nervosa? A prevalence study." British Journal of Psych, 218, 549-554.

Fairburn, C. G. (1983). "Bulimia: Its epidemiology and management." Psychiatric Annals, 13, 953-961.

Garfinkel, P. \& Garner, D. (1982). Anorexia nervosa: A multidimensional perspective. New York, NY: Brunner/Mazel.

Garfinkel, P. E., Garner, D. M., Rose, J., Darby, P. L., Brandes, J. S., O'Hanlon, J., \& Walsh, N. (1983). "A comparison of characteristics in the families of patients with anorexia nervosa and normal controls." Psychological Medicine, 13, 821-828.

Garner, D. M. \& Garfinkel, P. E. (1979). "The eating attitudes test: An index of the symptoms of anorexia nervosa." Psychological Medicine, 10, 647-656.

Gilligan, C. (1982). In a different voice. Cambridge, MA: Harvard University Press.

Hall, A. (1978). "Family structure and relationships of 50 female anorexia nervosa patients." Australian and New Zealand Journal of Psychiatry, 12, $\overline{263-268 .}$

Halmi, K. A., Falk, J. R., \& Schwartz, E. (1981). "Binge eating and vomiting: A survey of a college population." Psychological Medicine, 11, 697-706. 
Hollis, J. F., Carmody, T. P., Connor, S. L., Fey, S. G., \& Matarazzo, J. D. (1986). "The nutrition attitude survey: Associations with dietary habits. psychological and physical well-being, and coronary risk factors." Health Psychology, 5, (4), 359-374.

Horner, A. J. (1984). Object relations and the developing ego in therapy. New York, NY: Jason Aronson.

Hochschild, A. (1984). The managed heart. Berkeley, CA: University of California Press.

Hsu, L. K. G. (1983). "The etiology of anorexia nervosa." Psychological Medicine, 13, 231-238.

Hudson, W. W. (1982). The clinical measurement package: A field manual. Chicago, IL: Dorsey Press.

Humphrey, L. L. (1986). "Structural analysis of parent-child relationships in eating disorders." Journal of Abnormal Psychology, 95, (4), 395-402.

Humphrey, L. L., Apple, R. F., \& Kirschenbaum, D. S. (1986). "Differentiating bulimic-anorexic from normal families using interpersonal and behavioral observational systems." Journal of Consulting and Clinical Psychology, 54, (2), 190-195.

Johnson, C. (1985). "The initial consultation," in Handbook of Psychotherapy for Anorexia and Bulimia. Edited by Garner, D. \& Garfinkel, F. New York, NY: Guil ford Press.

Johnson, C. \& Flach, A. (1985). "Family characteristics of 105 patients with bulimia." American Journal of Psychiatry, 142, (11), 1321-1324.

Kalucy, R. S., Crisp, A. H. \& Harding, B. (1977). "A study of 56 families with anorexia nervosa." British Journal of Medical Psychology, 50, 310-305.

Kalucy, R. S., Crisp, A. H., Lacey, J. H., \& Harding, B. (1977). "Prevalence and prognosis in anorexia nervosa." Australian and New Zealand Journal of Psychiatry, 11, 251-257.

Kog, E. \& Vandereycken, W. (1985). Family characteristics of anorexia nervosa and bulimia: A review of the research literature." Clinical Psychology Review, $\underline{5}$, 159-180. 
Kog, E., Vertommen, H., \& Degroote, T. (1985). "Family interaction research in anorexia nervosa: The use and misuse of a self-report questionnaire." International Journal of Family Psychiatry, 6, (3), 227-243.

Minuchin, S., Rosman, B., \& Baker, L. (1978).

Psychosomatic families: Anorexia nervosa in context. Cambridge, MA: Harvard University Press.

Morgan, H. G. \& Russell, G. F. M. (1975). "Value of family background and clinical features as predictors of long-term outcome in anorexia nervosa: A four-year follow-up study of 41 patients." Psychological Medicine, 5, 355-371.

Orbach, S. (1986). Hunger strike: The anorectic's struggle as a metaphor for our age. New York, NY: W. W. Norton.

Ordman, A. M., \& Kirschenbaum, D. S. (1986). "Bulimia: Assessment of eating, psychological adjustment, and familial characteristics." International Journal of Eating Disorders, 5 , (5), 865-878.

Pope, H. G., Hudson, J. I., \& Jonas, J. M. (1986). "Bulimia in men: A series of 15 cases." The Journal of Nervous and Mental Disease, 174 (2), 117-119.

Pyle, R. L. \& Mitchell, J.E. (1986). "The prevalence of bulimia in selected samples." Adolescent Psychiatry, 13, 241-252.

Pyle, R. L., Mitchell, J. E., Eckert, E. D., Halvorson, P. A., Neuman, P. A., \& Goff, G. M. (1983). "The incidence of bulimia in college students." International Journal of Eating Disorders, 2, 75-85.

Reed, G. \& Sech, E. P. (1985). "Bulimia: A conceptual model for group treatment." Journal of Psychosocial Nursing, 23, (5), 16-21.

Ross, J. L. (1977) . "Anorexia nervosa: An overview." Bulletin of the Menninger Clinic, 4l, 418-436.

Seligman, E. (1976). "A psychological study of anorexia nervosa." Journal of Analytical Psychology, 21, 193-209. 
Selvini-Palazzoli, M. (1978). Self-starvation: From individual to family therapy in the treatment of anorexia nervosa. New York, NY: Jason Aronson.

Sours, J.A. (1974). "The anorexia nervosa syndrome." International Journal of Psychoanalysis, 55, 567-576.

Thoma, H. (1977). "On the psychotherapy of patients with anorexia nervosa." Bulletin of the Menninger Clinic, 41, 437-4452.

Yager, J. (1982). "Family issues in the pathogenesis of anorexia nervosa." Psychosomatic Medicine, 44, 43-60. 
APPENDIX A

QUESTIONNAIRE 
Please give your response to each question following the directions under each of the six sections. This is not a test. There are no right or wrong answers. The questionnaire usually takes $2 \overline{0}-30$ minutes to complete. This survey is part of a study of how current health and nutrition lifestyles are related to relationship patterns in the family in which you were raised. Your responses will be kept absolutely confidential. Any reports based on this survey will be presented using grouped data so that participants will be impossible to t.race.

I would be glad to answer any questions after you have completed the survey. If you experienced problems that are the result of your participation in this study, please contact the secretary of the Human Subjects Research and Review Committee, Office of Grants and Contracts, 303 Cramer Hall, Portland State University, 464-3417. You are free to withdraw from participation in this study at any time without jeopardizing your course grade or your relationship with Portland State University. Thank you for your time and cooperation. 
IDENTIFYING AND DEMOGRAPHIC INFORMATION

1. Sex Male

Female

2. Age (at closest birthday)

3. Race (check one) White Black Other (specify)

4. Marital Status (check one): Single Married Divorced Widowed Separated

5. What is your present primary role? (check one) Wage Earner Housewife or husband Student Other (specify)

6. Highest Occupational Level Attained: (circle one for each person)

1) Higher executive, proprietor of large concern, major professional (i.e., a doctor)

2) Business manager of large concern, proprietor of medium-sized business, lesser professional (i.e., en accountant)

3) Administrative personnel, owner of small, independent business, minor professional (i.e., a nurse), owner of large farm.

4) Clerical or sales worker, technician, owner of little business, owner of medium-sized farm.

5) Skilled manual employee, (i.e., a journeyman or master), owner of small business.

6) Machine operator, seriskilled employee, (i.e., an

apprentice), tenant farmer who owns little equipment.

7) Unskilled employee, sharecropper.

8) Does not apply (never worked in paid employment).

9) Information not available.

Self Father Mother

Self Father Mother

Self Father Mother

Self Father Mother

Self Father Mother

Self Father Mother

Self Father Mother

Self Father Mother

Self Father Mother

7. Highest Income Earned Annually During Career: (circle one for each person)

$$
\begin{aligned}
& \$ 0-5,000 \\
& \$ 5,000-10,000 \\
& \$ 10, \infty 00-15, \infty 00 \\
& \$ 15,000-20, \infty 00 \\
& \$ 20, \infty 00-25, \infty 00 \\
& \$ 25, \infty 00-30, \infty 00 \\
& \$ 30, \infty 00-40, \infty 00 \\
& \$ 40, \infty 00-50, \infty 00 \\
& \$ 50, \infty 00-75, \infty 00 \\
& \$ 75, \infty 00-100, \infty 00 \\
& \text { Greater than } \$ 100, \infty 00 \\
& \text { Don't know }
\end{aligned}
$$

Self Father

Self Father

Self Father

Self Father

Self Father

Self

Self

Self

Self

Self

Self

Self
Mother

Mother

Mother

Mother

Mother

Mother

Mother

Mother

Mother

Mother

Mother

Mother 
8. Employment Satisfaction: (circle one for each person)
1) Strongly dislike
2) Dislike
3) Neutral
4) Like
5) Strongly enjoy

Self Father

Mother

Self Father

Mother

Self Father

Self Father

Mother

Mother

Self Father Mother

9. Current living arrangement (check one): with parents or relative

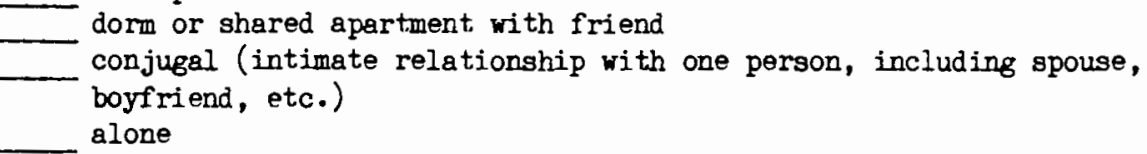

10. Indicate last year of school attended next to each person below:
$12345678 \quad 9101112 \cdot 1234$
M.A./M.S. Ph.D. Other (specify-include Grade School High School College Graduate

Indicate which level (i.e., 4 college, not just 4)

Self

Father

Mother

HEALTH AND NUTRITION HISTORY

11. Current weight:

12. Current height:

13. Desired weight:

Ibs.

feet and inches lobs.

14. How did you perceive your weight as a child between $6-12$ years of age? (circle one)

\begin{tabular}{ccccc} 
& & & \\
\hline Ext,remely & Somewhat & Normal & Somewhat & Extremely \\
Thin & Thin & Weight & Overweight & Overweight
\end{tabular}

15. At your current weight, do you feel you are (circle one):

\begin{tabular}{ccccc} 
& & & & \\
\hline Extremely & Somewhat & Normal & Somewhat & Extremely \\
Thin & Thin & Weight & Overweight & Overweight
\end{tabular}

16. Are you involved in an occupation that requires you to maintain a certain weight? Yes No Please explain:

18. How much does a two-pound weight gain or loss affect your feelings about yourself? (circle one)

\begin{tabular}{|l|l|l|l} 
& & & 1 \\
\hline Extremely & Very Much & Moderately & Slightly
\end{tabular}


19. What is your usual eating pattern: (check one)

1 large meal daily

2 meals daily

3 meals daily

snack throughout the day

20. Indicate the kinds of foods you usually eat:

Regular balanced mixed diet with foods from all four food groups (meat, fruit and vegetables, grain, dairy)

Regular balanced mixed diet with fish or fowl, but no red meat.

- Vegetarian diet with no mest, fish or fowl.

Fast foods or snack foods, foods that "are bad for me."

Whatever is handy - I don't pay particular attention to what I eat.

21. Show how much each statement applies to you with the following scale:

$0=$ Not at all; $1=$ A little bit; $2=$ Moderately; $3=$ Quite a bit; $4=$ Extremely

Even though I know that my way of eating is not good for me, I just can't seem to change my eating habits.

When it comes to food, I have no will power.

- My eating behavior is strongly correlated with my mood: I eat more when I'm bored, unhappy, feeling down, anxious, uptight, lonely, happy, tired, worn out, feeling unconfident (please circle particular ones that apply).

22. Check only those items that apply to you:

History of heart problem History of dizziness High blood pressure Bone or joint problem can be aggravated by exercise. Stomach or intestingl difficulties, with possible chronic vomiting.
Periods of self-induced vomiting. Indicate frequency Back problem or injury requiring medical treatment Cigarette smoker. Indicate daily consumption Alcohol intake. Indicate weekly number of drinks Take prescription drugs regularly-specify.

23. What are the attitudes of important people in your life (significant other, parents, friends, employer) about your attempts to gain or lose weight?

Negative (they disapprove or are resentful)

- Indifferent. (they don"t care or don"t help)

Positive (they encourage me and are understanding)

- I'm not trying to gain or lose weight.

24. What are the attitudes of important people in your life (significant other, parents, friends, employer) about your dietary habits?

Negative (they disapprove or are resentrul)

Indifferent (they don"t care or don"t help)

Positive (they encourage me and are understending) 
QUESTIONNAIRE - 4

25. Exercise preference and status: How of ten do you get vigorous, aerobic exercise of at least 20-30 minutes/session? What activities are you involved in? list each activity and how how of ten you do it.

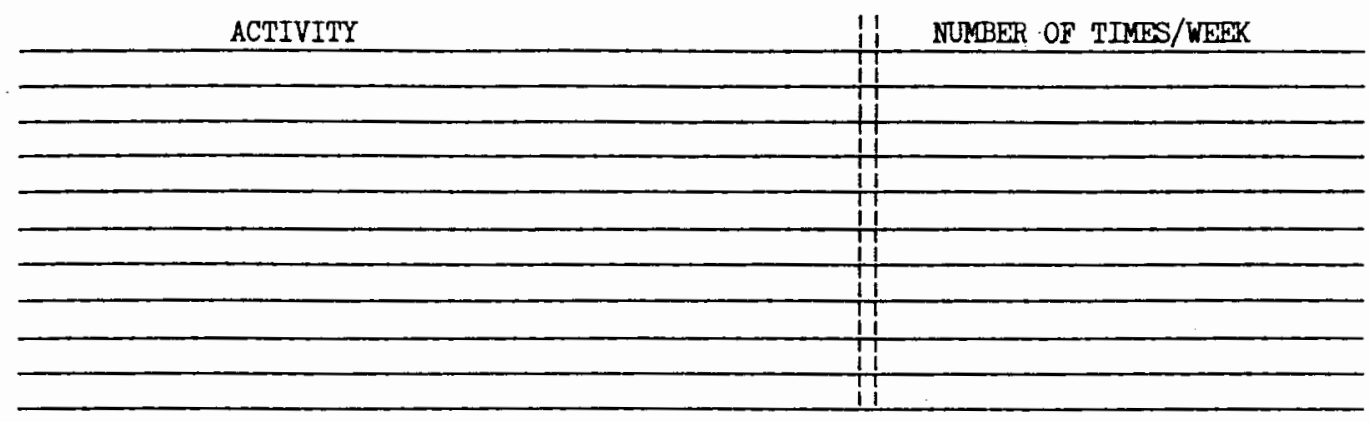




\section{FAMILY REILATIONSHIPS}

The following questions are designed to measure the degree of contentment you have in your relationship with each parent. Please answer each question as it reflects your feelings towards that parent. as you were growing up. Answer each iten as carefully and accurately as you can by circling a number beside each one as follows:

$1=$ Rarely or none of the time; $2=$ A little of the time; $3=$ Some of the time

$4=$ Good part of the time; $5=$ Most, or all of the time

Please indicate age when parent(s) divorced or died, and whether you are scoring for a step parent.

1. My father got on my nerves.

2. I got along well with my father.

3. I felt that I could really trust my father.

$\begin{array}{lllll}1 & 2 & 3 & 4 & 5 \\ 1 & 2 & 3 & 4 & 5 \\ 1 & 2 & 3 & 4 & 5 \\ 1 & 2 & 3 & 4 & 5 \\ 1 & 2 & 3 & 4 & 5 \\ 1 & 2 & 3 & 4 & 5 \\ 1 & 2 & 3 & 4 & 5 \\ 1 & 2 & 3 & 4 & 5 \\ 1 & 2 & 3 & 4 & 5 \\ & & & & \\ 1 & 2 & 3 & 4 & 5 \\ 1 & 2 & 3 & 4 & 5 \\ 1 & 2 & 3 & 4 & 5 \\ & & & & \\ 1 & 2 & 3 & 4 & 5 \\ 1 & 2 & 3 & 4 & 5 \\ 1 & 2 & 3 & 4 & 5 \\ 1 & 2 & 3 & 4 & 5 \\ 1 & 2 & 3 & 4 & 5 \\ 1 & 2 & 3 & 4 & 5 \\ & & & & 5 \\ 1 & 2 & 3 & 4 & 5 \\ 1 & 2 & 3 & 4 & 5 \\ 1 & 2 & 3 & 4 & 5 \\ 1 & 2 & 3 & 4 & 5 \\ 1 & 2 & 3 & 4 & 5 \\ 1 & 2 & 3 & 4 & 5 \\ 1 & 2 & 3 & 4 & 5\end{array}$

4. I disliked my father.

5. My father's behavior emberrassed me.

6. My father was too demanding.

7. I wished I had a different father.

8. I really enjoyed my father.

9. fother put too many limits on me.

10. My father interferod with my activities.

11. I resented my father.

12. I thought my father was terrific.

13. I hated my father.

14. My father was very patient with me.

15. I really liked my father.

16. I liked being with my father.

17. I felt like I did not love my father.

18. My father was very irritating.

19. I felt very angry toward my father.

20. I felt violent toward my father.

21. I felt proud of my father.

22. I wished my father was more like others I knew.

23. Hy father did not understand me.

24. I could really depend on my father.

25. I felt ashamed of my father. 5 5$$
5
$$ 
$1=$ Rarely or none of the time; $2=$ A little of the time; $3=$ Some of the time

$4=$ Good part of the time; $5=$ Most or all of the time

1. My mother got on my nerves.

2. I got along well with my mother.

3. I felt that I could really trust my mother.

$\begin{array}{lllll}1 & 2 & 3 & 4 & 5 \\ 1 & 2 & 3 & 4 & 5 \\ 1 & 2 & 3 & 4 & 5\end{array}$

4. I disliked my mother.

5. Mother's behavior embarrassed me.

6. My mother was too demanding.

$\begin{array}{lllll}1 & 2 & 3 & 4 & 5\end{array}$

$\begin{array}{lllll}1 & 2 & 3 & 4 & 5\end{array}$

7. I wished I had a different mother.

8. I really enjoyed my mother.

9. My mother put too many limits on me.

10. My mother interfered with my activities.

11. I resented my mother.

12. I thought my mother was terrific.

13. I hated my mother.

14. My mother was very patient with me.

15. I really liked my mother.

16. I liked being with my mother.

17. I felt like I did not love my mother.

18. My mother was very irritating.

19. I felt very angry toward my mother.

20. I felt violent toward my mother.

21. I felt proud of my mother.

22. I wished my mother was more like others I knew.

23. My mother did not understand me.

24. I could really depend on my mother.

25. I felt ashamed of my mother.

$\begin{array}{lllll}1 & 2 & 3 & 4 & 5\end{array}$

$\begin{array}{lllll}1 & 2 & 3 & 4 & 5\end{array}$

$\begin{array}{lllll}1 & 2 & 3 & 4 & 5 \\ 1 & 2 & 3 & 4 & 5\end{array}$

$\begin{array}{lllll}1 & 2 & 3 & 4 & 5 \\ 1 & 2 & 3 & 4 & 5 \\ 1 & 2 & 3 & 4 & 5\end{array}$

$\begin{array}{lllll}1 & 2 & 3 & 4 & 5 \\ 1 & 2 & 3 & 4 & 5 \\ 1 & 2 & 3 & 4 & 5\end{array}$

$\begin{array}{llll}2 & 3 & 4 & 5 \\ 2 & 3 & 4 & 5 \\ 2 & 3 & 4 & 5\end{array}$

$\begin{array}{lllll}1 & 2 & 3 & 4 & 5\end{array}$

$\begin{array}{lllll}1 & 2 & 3 & 4 & 5\end{array}$

$\begin{array}{lllll}1 & 2 & 3 & 4 & 5\end{array}$

$\begin{array}{lllll}1 & 2 & 3 & 4 & 5 \\ 1 & 2 & 3 & 4 & 5 \\ 1 & 2 & 3 & 4 & 5 \\ 1 & 2 & 3 & 4 & 5\end{array}$


For the following set of questions, mark the answer that best fits how you saw your family as you were growing up. If you feel that your answer is between two of the labeled numbers (the odd numbers), then choose the even number that is between them.

Yes
Fits our
family
very well

1. Family members paid attention to each other's feelings.

2. Our family would have rather done things together than with other people.

3. We all had a say in family plans.

4. The grownups in this family understood and agreed on family decisions.

5. The grownups in the family competed and fought with each other.

6. There was closeness in my family but each person was allowed to be special and different.

7. We accepted each other's friends.

8. There was confusion in our family because there was no leader.

9. Our family members touched and hugged each other.

10. Family members put each other down.

11. We spoke our minds, no matter what.

12. In our home, we felt loved.

13. Even when we felt close, our family was embarrassed to admit it.
SOME:

Pits our family some.
NO:

Does not fit our family.

$$
2
$$

t.


QUESTIONNAIRE - 8

Yes

Fits our

family

very well
NO:

Does not

fit our

family.

14. We argued a lot and never solved problems.

2

3

15. Our happiest times were at home.

16. The grownups in this family were strong leaders.

2

3

17. The future looked good to our family.

2

3

18. We usually blamed one person in our family when things weren ${ }^{-} t$ going right.

2

3

19. Family members went their own way most of the time.

20. Our family was proud of being close.

21. Our family was good at solving problems together.

22. Family members easily expressed warmth and caring towards each other.

23. It was okay to fight and yell in our family.

24. One of the adults in this family had a favorite child.

25. When things went wrong, we blamed each other.

27. Our family members would have rather done things with other people than together.

28. Family members paid attention to each other and listened to what was said.

29. We worried about hurting each other"s feelings. 


\section{QUESTIONNAIRE - 9}

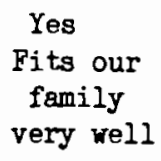

SOME:

Fits our family some.
No: Does not fit our family.

30. The mood in my family was usually sad and blue.

$\begin{array}{lllll}1 & 2 & 3 & 4 & 5 \\ 1 & 2 & 3 & 4 & 5\end{array}$

31. We argued a lot.

2

4

5

33. My family was happy most of the time.

2

3

4

5

34. Each person took responsibility for his/her behavior.

2

3

4

5

35. On a scale of 1 to 5 , I would rate my family as:
My fomily functioned
23
very well together.
4 My family did not function well together at all. We really needed help.

36. On a scale of 1 to 5 , I would rate the independence in my family as:
1 2 3
(No one was independent. There were no open argu- ments. Family members relied on each other for satisfaction rather than on outsiders.)
(Sometimes independent. There were some disagree- ments. Family members found satisfaction both within and outside of the family.)

5

(Family members usually went their own way. Disagreements were open. Family members looked outside of the family for satisfaction.) 
This final section includes questions regarding aspects of your heslth and nutritional lifestyle. The extent that you are able to answer them, I would appreciate it if you could make as complete a reply as possible.

Please circie your response in the column which applies best to each of the numbered statements. Please answer each question carefully.

$\begin{array}{lll}\text { Very } & \\ \text { Always Often Often Sometimes Rarely Never }\end{array}$

1. Like eating with other people.

$\begin{array}{llllll}1 & 2 & 3 & 4 & 5 & 6\end{array}$

2. Prepare foods for others but do not eat what I cook.

3. Become anxious prior to eating.

4. Am terrified about being overweight.

5. Avoid eating when I am hungry.

6. Find myself preoccupied with food.

12

3

4

5

6

7. Have gone on eating binges where I feel that I may not be able to stop.

8. Cut my food into small pieces.

12

3

4

56

9. Aware of the calorie content of foods that I eat.

10. Particularly avoid foods with a high carbohydrate content (e.g., bread, potatoes, rice, etc.).

11. Feel bloated after meals.

12. Feel that others would prefer if I ate more.

13. Induce myself to vomit after I have eaten.

$\begin{array}{llllll}1 & 2 & 3 & 4 & 5 & 6\end{array}$

14. Feel extremely guilty after eating.

2

15. Am preoccupied with a desire to be thinner. 
QUESTIONNAIRE - 11

$\begin{array}{ll}\text { Very } & \\ \text { Always Often Often Sometimes Rarely Never }\end{array}$

16. Exercise strenuously to burn off celories.

17. Weigh myself several times a day.

1

$$
2
$$

3

4

5

6

18. Like my clothes to fit tightly.

23

4

56

18. Like my clothes to fit tightly.

23

4

56

19. Enjoy eating meat.

20. Wake up early in the morning.

23

4

56

21. Eat the same foods day after day.

23

4

56

22. Think about burning up calories when I get exercise.

23

4

5. 6

23. Other people think that I am too thin.

23

4

56

24. Am preoccupied with the thought of having fat on my body.

23

4

56

25. Take longer than others to eat my meals.

26. Enjoy eating at restaurants.

27. Take laxatives for weight control.

28. Avoid foods with sugar in them.

29. Eat diet foods.

30. Feel that food controls my life.

31. Display self control around food.

32. Feel that others pressure me to eat.

23

4

$5 \quad 6$

33. Give too much time and thought to food.

34. Suffer from constipation.

23

4

56

1

23

$4 \quad 5 \quad 6$

35. Feel uncomfortable after eating sweets.

36. Engage in dieting behavior.

23

4

56

1

23

4

. 6

$\begin{array}{llllll}1 & 2 & 3 & 4 & 5 & 6 \\ 1 & 2 & 3 & 4 & 5 & 6\end{array}$


QUESTIONNAIRE - 12

$\begin{array}{ll}\text { Very } & \\ \text { Always Often Often Sometimes Rarely Never }\end{array}$

37. Like my stomach to be empty.

38. Enjoy trying new rich foods.

$\begin{array}{llllll}1 & 2 & 3 & 4 & 5 & 6 \\ 1 & 2 & 3 & 4 & 5 & 6\end{array}$

39. Have the impulse to vomit after meals.

$\begin{array}{llllll}1 & 2 & 3 & 4 & 5 & 6\end{array}$

40. Feel miserable or annoyed by my eating habits.

41. Am very private in my eating and weight control habits.

42. Have the impulse to take laxatives to "get rid of food."

$\begin{array}{llllll}1 & 2 & 3 & 4 & 5 & 6\end{array}$

43. Become physically ill as a result of my eating habits.

$\begin{array}{llllll}1 & 2 & 3 & 4 & 5 & 6\end{array}$

44. Put a number in the appropriate space to the right of each item below:

Number of times per/

Day Week Month Year

a. Eating binges (question \#7 above)

b. Vomiting after mesls (question \#13 above)

c. Laxatives to control weight (question \#27 above)

d. Number of times began a diet in the last year. 
APPENDIX B

SCORING FOR CUT-OFF SCORES FOR INTERMEDIATE GROUP ON EAT 
This final section includes questions regarding aspects of your health and mutritional lifestyle. The extent that you are able to answer them, I would appreciate it if you could make as complete a reply as possible.

Please circle your response in the column which applies best to each of the numbered statements. Please answer each question carefully.

$\begin{array}{ll}\text { Very } & \\ \text { Always Often Often Sometimes Rarely Never }\end{array}$

1. Like eating with other poople.

$\begin{array}{llllll}1 & 2 & 3 & 4 & 5 & 6\end{array}$

2. Prepare foods for others but do not eat what I cook.

(3) Become anxious prior to eating.

(4) All terrified about being overweight.

5. Avoid eeting when I an hungry.

(6) Find myself preoccupied with food.

$\begin{array}{llllll}1 & 2 & 3 & 4 & 5 & 6 \\ 1 & 2 & 3 & 4 & 5 & 6\end{array}$

(2. Have gone on eating binges where I feel that I may not be able to stop.

8. Cut my food into amall pieces.

(2) (3)

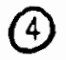

56

(9) Aware of the calorie content of foods that I eat.

23

(2) 3

4

56

12

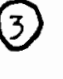

4

5

6

10. Particularly avoid foods with a high carbohydrate content (e.g., bread, potatoes, rice, etc.).

11. Feel bloated after neals.

1

(3)

(4)

6

123

4

6

12. Feel that others would prefer if I ate more.

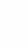

(2)

(3)

4

5

6

(13) Induce myself to vomit after I have eaten.

(14) Feel extremely guilty after exting.

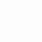

(12. Am preoccupied with a desire to be thinner.

1

(2)

(3)

(4)

(4)

56

23

(4)

56

1

(4) $5 \quad 6$


QUESTIONNAIRE - 11

$\begin{array}{ll} & \text { Very } \\ \text { Always Often Often Sometimes Rarely Never }\end{array}$

16. Exercise strenuously to burn off calories.

(17. Weigh myself several times a day.

1

18. Like my clothes to fit tightly.

19. Enjoy eating meat.

20. Wake up early in the morning.

21. Eat the same foods day after day.

22. Think about burning up calories when I get exercise.

23. Other people think that I em too thin.

24. An preoccupied with the thought of having fat on my body.

(2) 3

4

6

25. Take longer than others to eat my meals.

26. Enjoy eating at restaurants.

23

4

5

6

(27) Take laxatives for weight. control.

23

$4 \quad 5 \quad 6$

28. Avoid foods with sugar in them.

23

(4) $5 \quad 6$

(29) Eat diet foods.

23

4

56

30. Feel that food controls my life.

23

(4) 56

31. Display self control around food.

2

(3)

(4) $5 \quad 6$

32. Feel that others pressure me to eat.

23

(33) Give too much time and thought to rood.

23

4

6

34. Suffer from constipation.

35. Feel uncomfortable after eating sweets.

23

36. Engage in dieting behavior. 
37. Like my stomach to be empty.

38. Enjog trying new rich foods.

39. have the impulse to vomit after meals.

40. Feel miserable or annoyed by my eating habits.

41. Am very private in my eating and veight control habits.

42. Have the impulse to take laxatives to "get rid of food."

43. Become physically ill as a result of my eating habits.

$\begin{array}{llllll}1 & 2 & 3 & 4 & 5 & 6 \\ 1 & 2 & 3 & 4 & 5 & 6\end{array}$

1 (2) (3) 5 (3)

$\begin{array}{llllll}1 & 2 & 3 & 4 & 5 & 6\end{array}$

$\begin{array}{llllll}1 & 2 & 3 & 4 & 5 & 6\end{array}$

$\begin{array}{llllll}1 & 2 & 3 & 4 & 5 & 6\end{array}$

$\begin{array}{llllll}1 & 2 & 3 & 4 & 5 & 6\end{array}$

44. Put a number in the appropriate space to the right of each item below:

$$
\text { Number of times per/ }
$$

Day Week Month Year
a. Eating binges (question $\$ 7$ above)
b. Vomiting after meals (question \#13 above)
c. Laratives to control weight (question \#27 above)
d. Number of times began a diet in the last year. 


\section{APPENDIX C}

PRIMARY ANALYSIS: DESCRIPTIVE STATISTICS OR DEMOGRAPHIC AND FAMILY VARIABLES FOR SAMPLE OVERALL AND FOR MALE AND FEMALE SAMPLES 


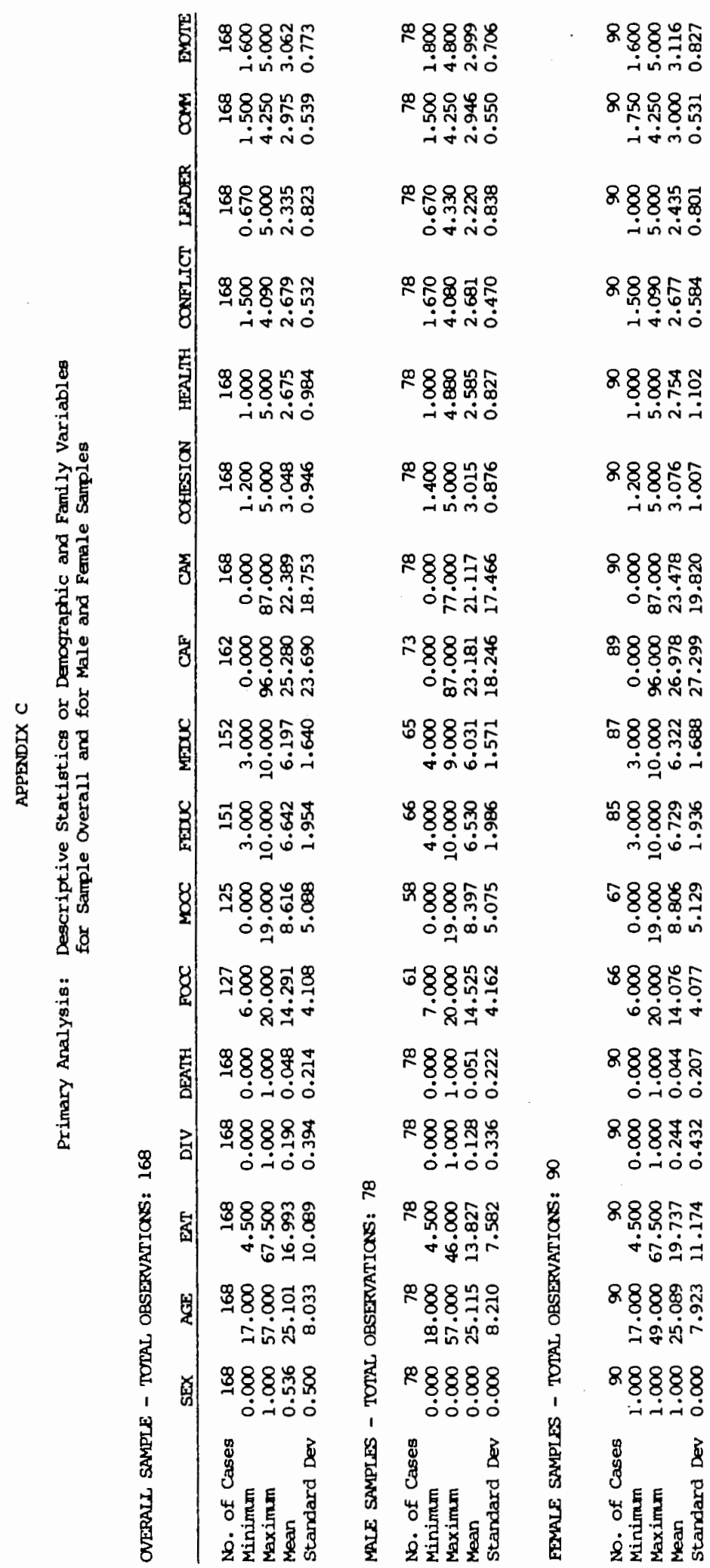


APPENDIX D

PRIMARY ANALYSIS: PEARSON PRODUCT MOMENT CORRELATIONS ON ALL PAIRS OF VARIABLES FOR SAMPLE OVERALI AND FOR MALE AND FEMALE SAMPLES 


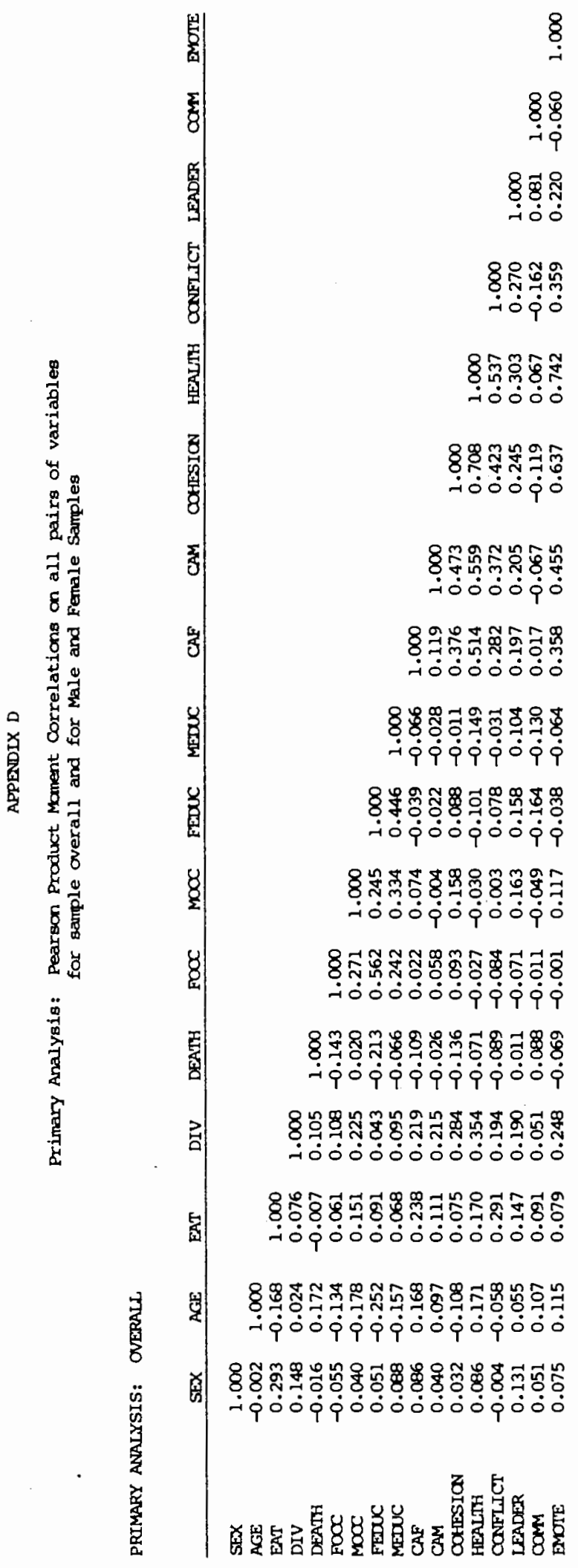




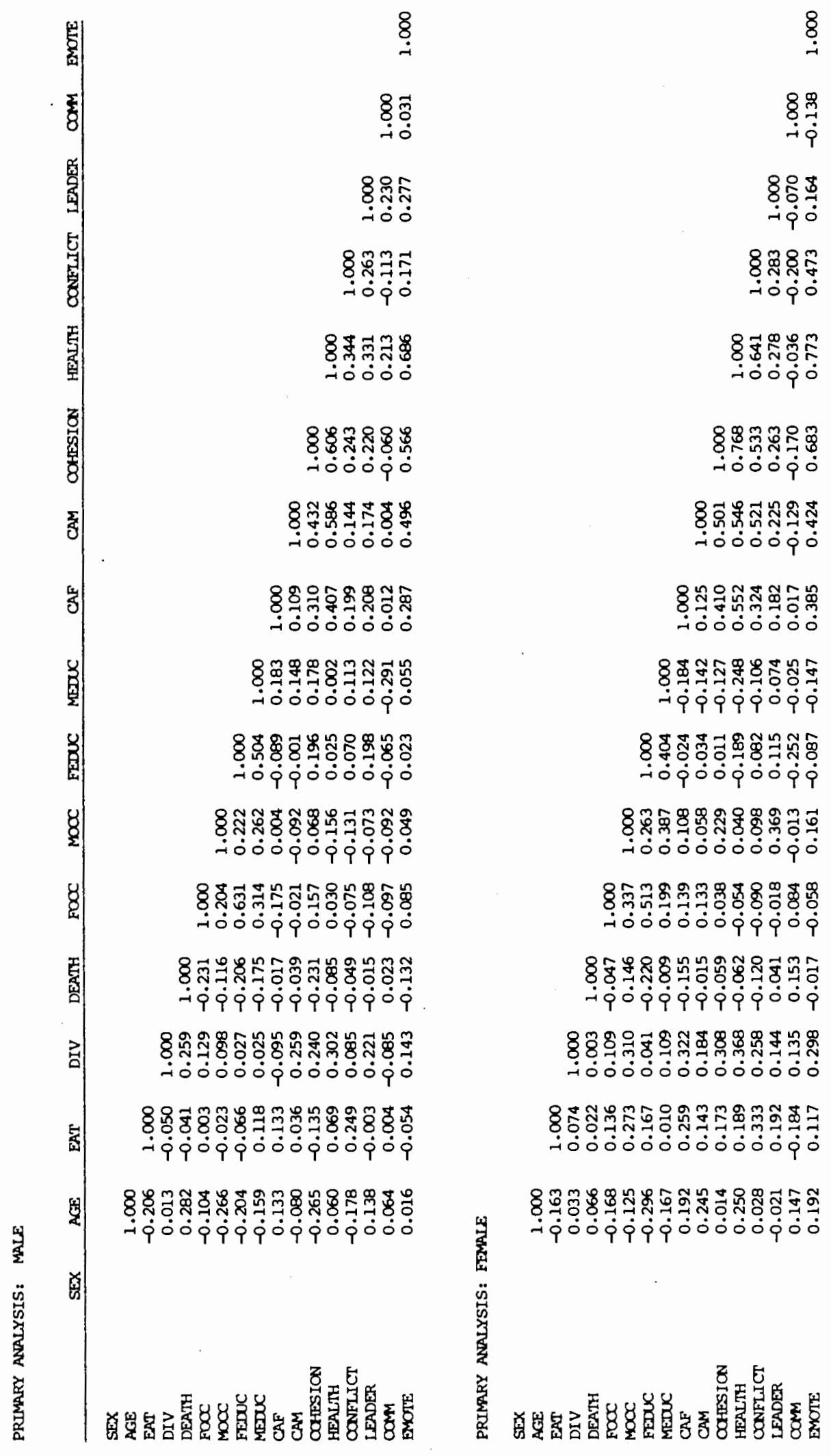


APPENDIX E

SCORING FOR EATING DISORDER SUBDIMENSIONS 


\section{APPENDIX E}

\section{EATING DISORDER SUBDIMENSIONS}

Refer to Appendix A for complete questionnaire. Item inclusion is as follows:

EATNEEDS: NO. $2,3,5,11,14,31,37$, and 42

EATCNTRL: NO. $10,13,21$, and 31

EATPHPOW: NO. 5, 16, 31, and 37

EATSOCPW: NO. $1,2,12,23$, and 32

AN : NO. $5,10,12,18,21,28,31$, and 32

$\mathrm{BU}$ : NO. 7, 13, 27 and 42 


\section{APPENDIX F}

SECONDARY ANALYSIS: DESCRIPTIVE STATISTICS ON EATING DISORDER AND FAMILY SUBDIMENSIONS FOR SAMPLE OVERALL AND FOR MALE AND FEMALE SAMPLES 


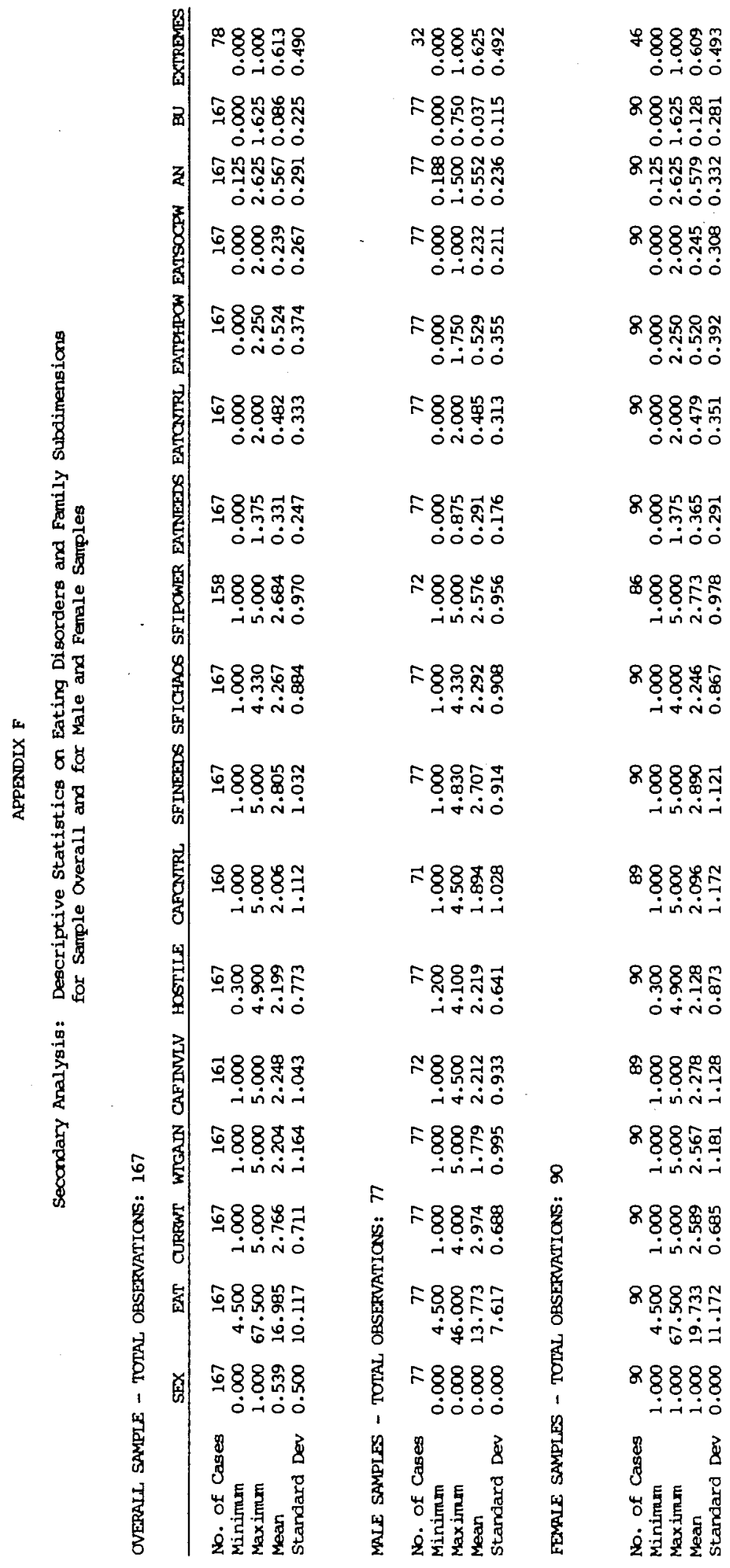


APPENDIX G

SECONDARY ANALYSIS: PEARSON PRODUCT MOMENT CORRELATIONS ON ALL PAIRS OF VARIABLES FOR SAMPLE OVERALL AND FOR MALE AND FEMALE SAMPLES 


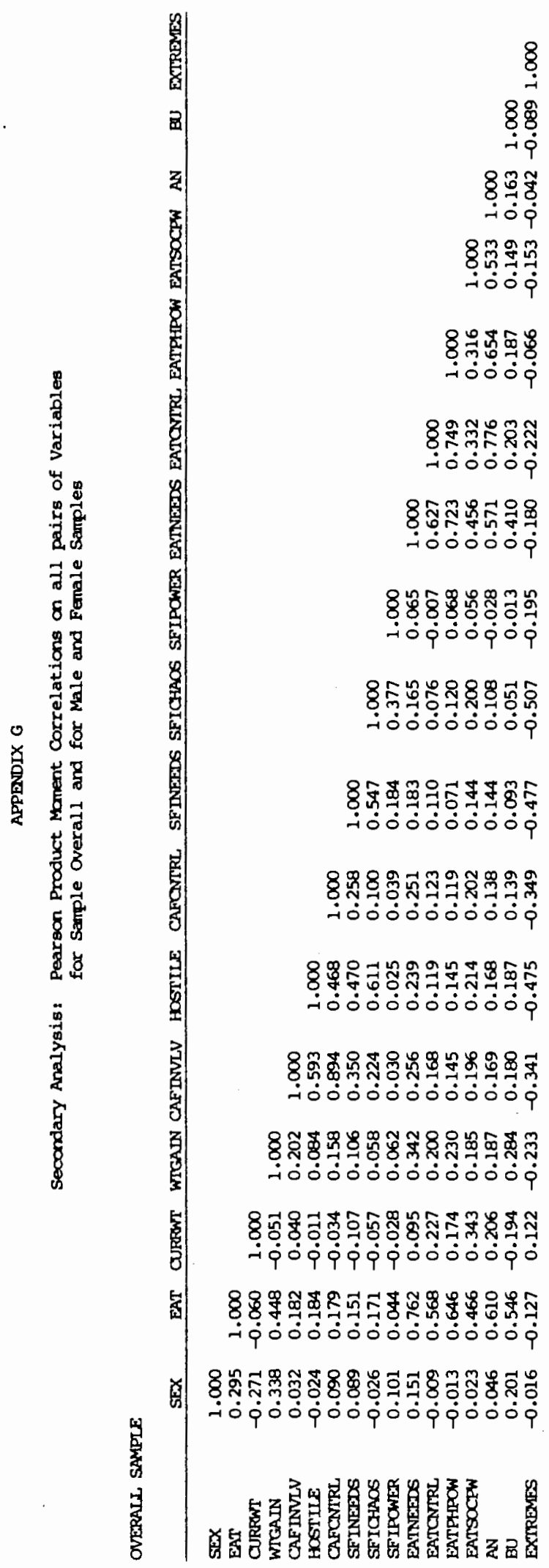




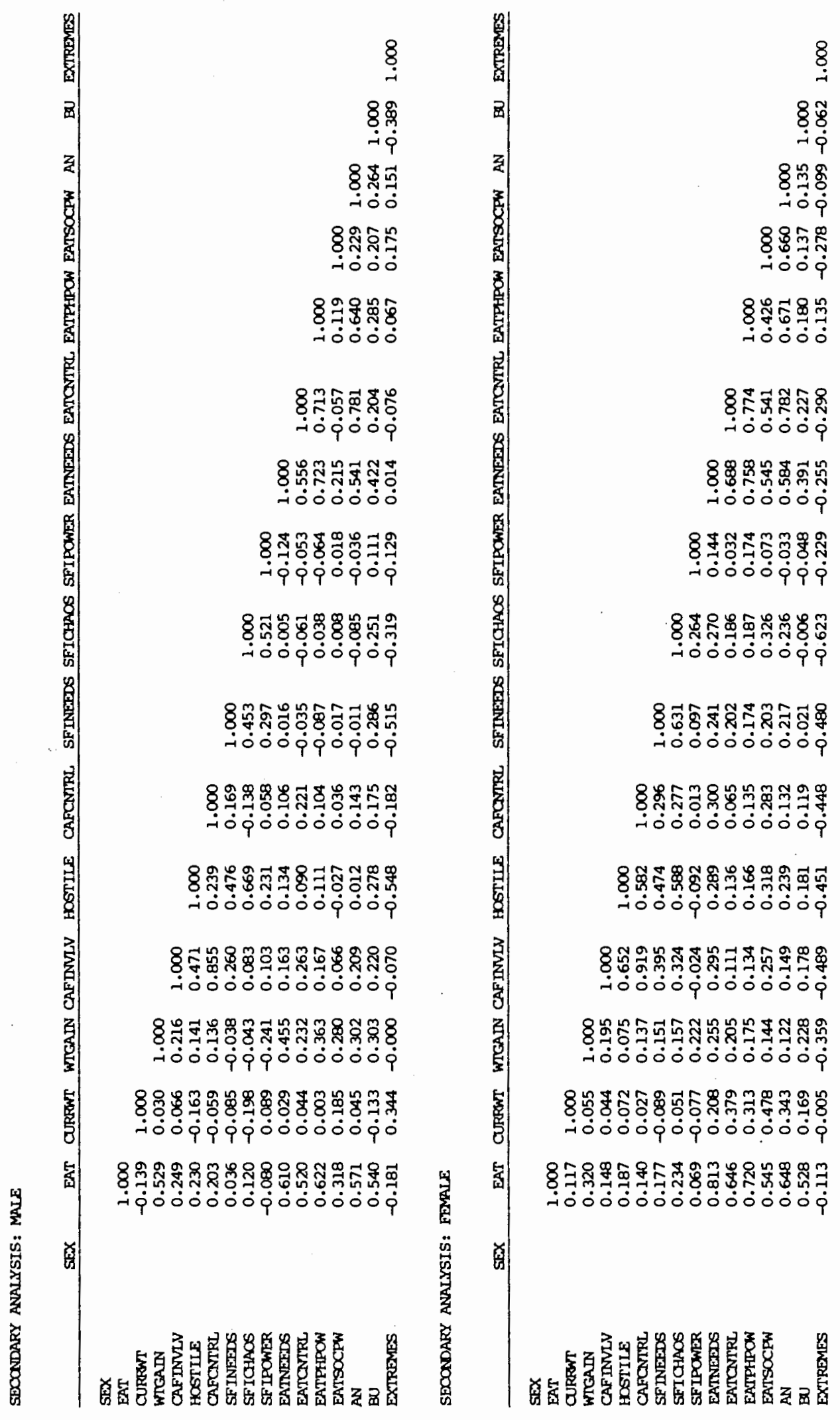

